2013

\title{
THE EFFECTS OF MODELING INSTRUCTION ON STUDENT LEARNING OF A NEWTONIAN FORCE CONCEPT
}

Daniel W. Kilpela

Michigan Technological University

Follow this and additional works at: https://digitalcommons.mtu.edu/etds

Part of the Education Commons

Copyright 2013 Daniel W. Kilpela

\section{Recommended Citation}

Kilpela, Daniel W., "THE EFFECTS OF MODELING INSTRUCTION ON STUDENT LEARNING OF A NEWTONIAN FORCE CONCEPT", Master's report, Michigan Technological University, 2013.

https://doi.org/10.37099/mtu.dc.etds/606

Follow this and additional works at: https://digitalcommons.mtu.edu/etds

Part of the Education Commons 
THE EFFECTS OF MODELING INSTRUCTION ON STUDENT LEARNING OF A NEWTONIAN FORCE CONCEPT

By

Daniel W. Kilpela

\begin{abstract}
A REPORT
Submitted in partial fulfillment of the requirements for the degree of MASTER OF SCIENCE

In Applied Science Education
\end{abstract}

MICHIGAN TECHNOLOGICAL UNIVERSITY

2013

(C) 2013 Daniel W. Kilpela 

This report has been approved in partial fulfillment of the requirements for the Degree of MASTER OF SCIENCE in Applied Science Education.

Department of Coginitive and Learning Sciences

Report Advisor: Kedmon N. Hungwe

Committee Member: Bradley H. Baltensperger

Committee Member: Kris G. Mattila

Department Chair: Bradley H. Baltensperger 


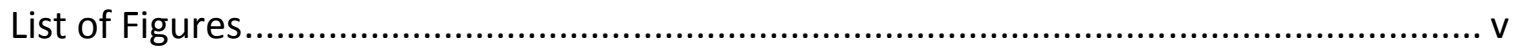

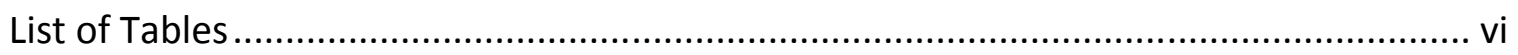

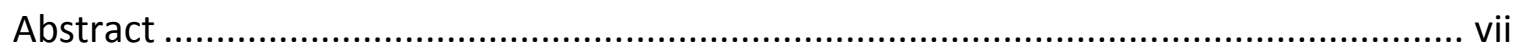

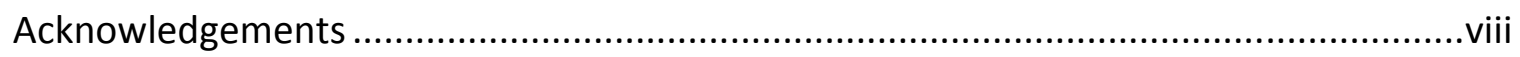

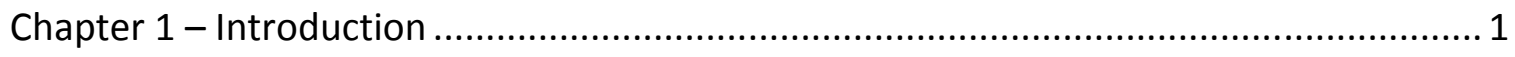

The Modeling Workshop .................................................................... 4

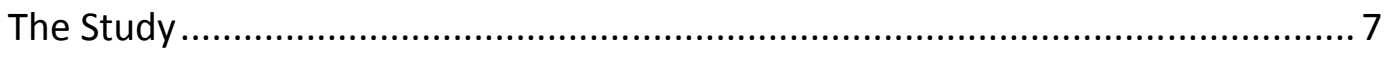

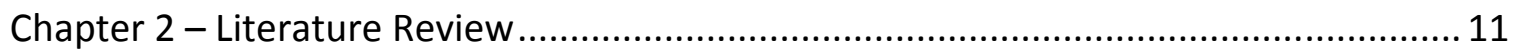

The Importance of Student Preconceptions................................................. 12

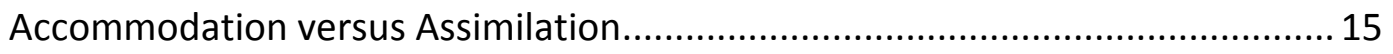

The Modeling Method of Instruction ......................................................... 17

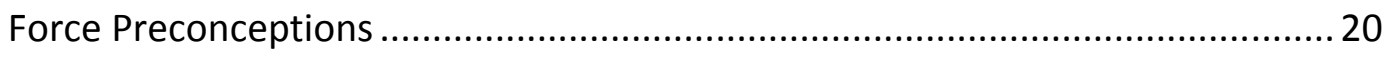

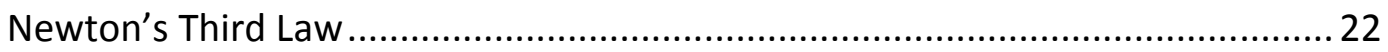

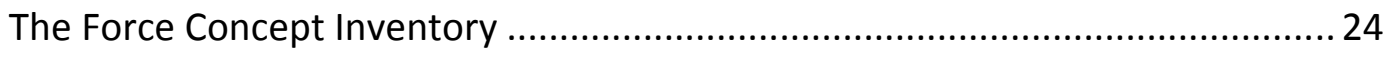

"For every" statements and the problem with "per" ...................................... 28 


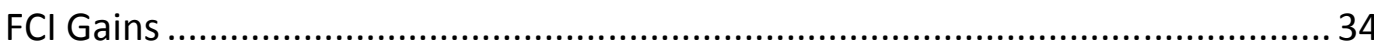

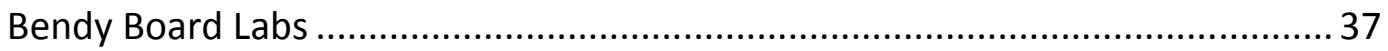

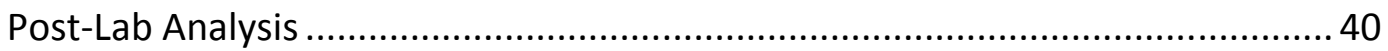

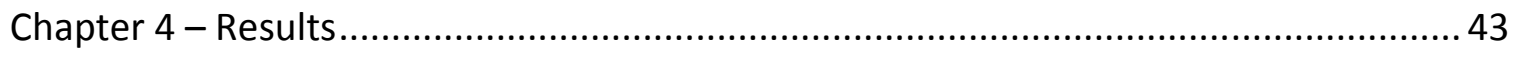

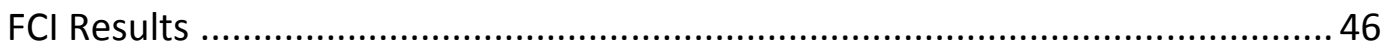

FCl Posttest Score Distributions .......................................................... 51

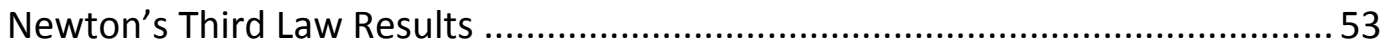

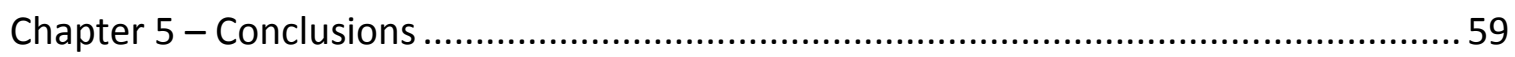

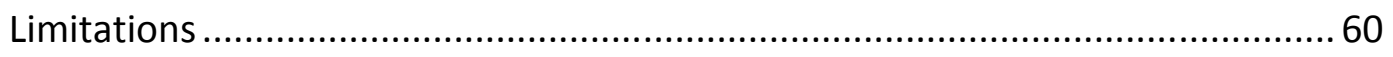

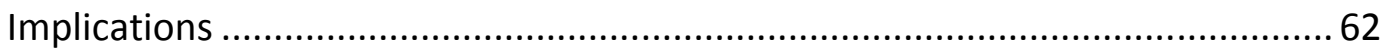

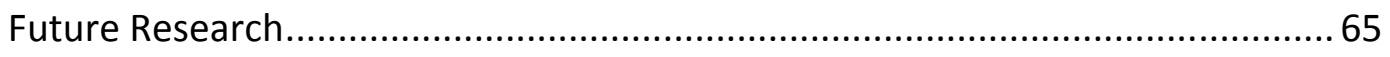

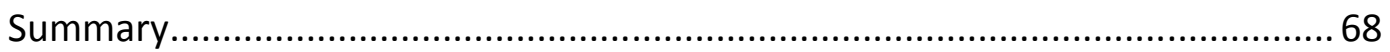

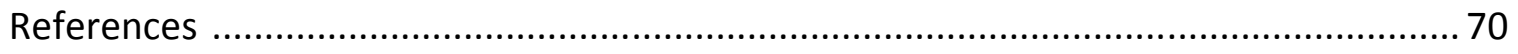




\section{List of Figures}

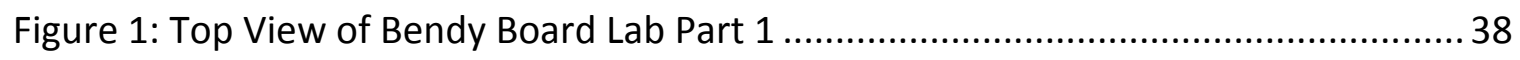

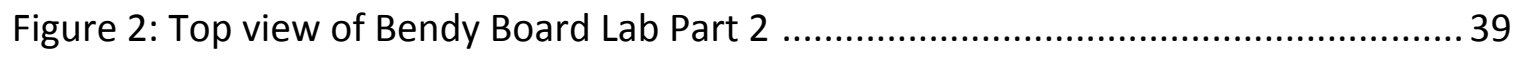

Figure 3: Side View of Bendy Board Lab Part 2 .................................................. 40

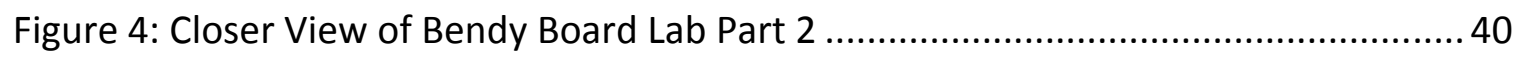

Figure 5: Group A FCI Posttest Score Distribution .................................................. 51

Figure 6: Group B FCl Posttest Score Distribution ................................................ 52

Figure 7: Group C FCI Posttest Score Distribution ................................................. 52

Figure 8: Mechanical Spring Scale Version of Bendy Board Lab Part 1 ......................... 55 


\section{List of Tables}

Table 1: FCl Results for Groups A, B, C

Table 2: Results for Newton's Third Law related FCl items ........................................5 57 


\begin{abstract}
This study explores the effects of modeling instruction on student learning in physics. Multiple representations grounded in physical contexts were employed by students to analyze the results of inquiry lab investigations. Class whiteboard discussions geared toward a class consensus following Socratic dialogue were implemented throughout the modeling cycle. Lab investigations designed to address student preconceptions related to Newton's Third Law were implemented. Student achievement was measured based on normalized gains on the Force Concept Inventory. Normalized $\mathrm{FCl}$ gains achieved by students in this study were comparable to those achieved by students of other novice modelers. Physics students who had taken a modeling Intro to Physics course scored significantly higher on the $\mathrm{FCl}$ posttest than those who had not. The $\mathrm{FCl}$ results also provided insight into deeply rooted student preconceptions related to Newton's Third Law. Implications for instruction and the design of lab investigations related to Newton's Third Law are discussed.
\end{abstract}




\section{Acknowledgments}

I would like to thank my advisor, Dr. Kedmon Hungwe for his guidance and patience with me during the years leading up to the completion of the project. In addition to Dr. Hungwe, I am grateful to rest of my committee, Dr. Kris G. Mattila and Dr. Bradley $\mathrm{H}$. Baltensperger for helping to make this a reality. As a teacher, I owe a great deal to Don Pata and Laura Ritter for facilitating the Modeling Workshop that I attended in the summer of 2011. The workshop was a turning point in my career. I would also like to thank my parents Don and Marja and my four brothers Mikael, Samuel, David and Jonathan for their support. Finally, I wish to thank my wife Gwen. She believed in me and provided excellent feedback and encouragement. 


\section{Chapter 1 - Introduction}

During the summer of 2011 I attended a three week workshop on the Modeling Method of Instruction in Physics in Troy, MI. I had just completed my ninth year of teaching science at Spring Lake High School and was excited to have recently begun teaching Physics and Intro to Physics classes instead of other physical science and math classes.

I was consumed with making the physics course the best it could be; I incorporated many lab activities, demos and video clips, even a rocket project, but despite all of this, the class had a very traditional teacher-centered atmosphere. I had developed good rapport with my students by scheduling evening "homework help night" sessions and continually developing new and interesting lab exercises for them to engage in. Students felt comfortable coming to me for help and did so frequently. I had even started to utilize some bridging analogy techniques in my teaching based on the ongoing research I was doing in my prior attempts to finish my MS-ASE capstone project. It wasn't until the summer 2011 modeling workshop that the pieces started to come together. I had many "aha" moments during the workshop and was excited to put what I had learned into practice during the 2011 school year.

In my physics teaching experience, I had found one thing to be true- students have a lot of life experience related to Newtonian mechanics. They have been observing 
things in motion or being influenced by various forces every day they have been alive. Naturally they have constructed ways of understanding these phenomena. Many of my students can recite Newton's Laws and use scientific terms like, velocity, acceleration, force, energy, momentum, etc., but this does not guarantee a functional understanding of the related concepts. Some have thought about these ideas more deeply and may have developed a more sophisticated understanding during their elementary and middle school years. Despite this, it is safe to say that on average they still have many preconceptions that hinder the development of a scientific understanding of Newtonian mechanics. Experiences play a valuable role in future learning, but the current understanding of a concept often makes it difficult to revisit those experiences and to view them differently.

Students often have deeply rooted ideas about how the physical world works. After all, these ideas have been their foundation for understanding or inquiring about events they witness on a daily basis. Physics terms are often used in sports broadcasts, movies, lyrics, and casual conversation, but the meanings these words carry in every day conversation may be very different than their meaning in a physics context. Nevertheless, students adopt these terms thus furthering their own "physics" understanding. This dynamic is an important player in student understanding in the classroom. Certain language may serve its intended purpose in a non-scientific context but when students use these same terms in physics class, often with much higher 
frequency and carrying entirely different meanings, we should not be surprised to find our students easily confused.

What I found refreshing in the modeling workshop was the emphasis on the actual meaning and context of the concepts being learned. I realized that using scientific vocabulary for the sake of "covering it" did more harm than good. Only after meaning has been attached to terms, symbols or equations, can they be effectively used to communicate scientific ideas. Before attending the workshop, I had launched into the introductory kinematic equations as a logical beginning for the first week of physics class. Surely position, displacement, speed, velocity and acceleration wouldn't be something we needed to spend much time on. But time and time again I was puzzled at how difficult it was for students to solve what I thought were simple motion problems or graphing exercises. Clearly my students' understandings of these equations were different than mine. I often found that they had no concrete context to give meaning to events described in the story problems they were solving.

I was on the verge of realizing the strategies I was using were ineffective. My students definitely learned some physics, but the structure of the course and the learning style being rewarded was not one which encouraged thoughtful development of ideas and brought about genuine conceptual change. At times I realized the need for some hands-on learning and would add a lab after we covered some of the preliminary material. Looking back I can see these lab exercises were very valuable but simply 
placed out of sequence. It became very clear to me during the modeling workshop that the labs were not something to do afterward as simply an application but instead they were logical starting points for a unit. The labs served as a context for discussions, opportunities to discover new information and provided new tools to advance scientific understanding.

Traditionally, much of what I had done as a teacher had short-circuited this process. I employed some discrepant event demonstrations and had some brief class discussions, but rarely allowed my students to struggle, inquire or discuss their ideas for more than a short time. I would nearly always give them the scientific explanation within minutes of the demonstration, robbing them of the opportunity to make the discoveries for themselves. If students really struggled with a concept, my focus would be on finding a better way of explaining it. The biggest problem was my belief that an isolated explanation, devoid of meaningful context, could significantly change their understanding.

\section{The Modeling Workshop}

The workshop was structured much like a classroom only with teachers as students. Roughly twenty five science and physics teachers attended. Physics expertise varied much like an actual classroom. We were instructed to try our best to act as our students would during most of the workshop so that the facilitators could model realistic classroom discussions, labs, and group work. During the workshop we covered 
most of the curriculum, performing lab investigations, practicing whiteboard discussion facilitation, working through homework assignments, etc. By working all day at an accelerated pace, we were able to cover many units of study as we witnessed and took part in a modeling approach to teaching Newtonian mechanics.

Each unit would begin with at least one lab investigation which was designed to highlight the relevant concepts in the unit and to serve as a building block for further investigations. For example, analyzing the motion of battery powered toy buggies served as a very simple, yet rich context for the constant velocity unit. Lab notebooks were used and data was collected and organized in a way that had been agreed upon by the entire class during the first lab activity. The idea of multiple representations, or expressing ideas in a variety of ways, was emphasized. Data was organized in tables and plotted on a graph, and computers were used to find the best-fit curve and equation to describe the data. Equations were always given physical meaning rather than the generic $y=m x+b$ form, for example. We were encouraged to insert words into equations instead of using symbols. A powerful representation that gave more meaning to our equations were "for every" statements. These were sentences describing the relationship between the variables in question, such as time and position, and they brought a lot of clarity, particularly to the understanding of linear relationships.

After collecting and analyzing the data each lab group presented their findings and a lengthy post-lab whiteboard discussion ensued. These post-lab whiteboard 
discussions were vital in making comparisons between groups and noticing patterns. The workshop facilitators modeled Socratic questioning techniques that could be used during these discussions. Following this phase of the unit came the deployment phase where worksheets specifically designed to address key concepts and misconceptions were assigned. The questions and problems were often intentionally somewhat openended. This allowed students to identify initial assumptions that were made in the problems rather than skip over clearly stated initial conditions, which in my teaching experience had happened all too often. The problems ranged from qualitative to quantitative but always stressed critical thinking skills and were structured in such a way as to scaffold the construction of new scientific knowledge.

Following completion of these assignments, many of the problems were presented using whiteboards. This again provided an opportunity for us as students to learn from each other. Consensus building was encouraged as a way of providing closure. It became very clear that effective facilitation would not be easy. Students would invariably clamor for the "right answer" from the teacher. The challenge as a teacher would be to direct the questions back to the group, focus the discussion and clarify questions or statements made. Laying the proper foundation for this type of class discourse was clearly going to be a challenge but also one that seemed very worthwhile in the long run. My hope was that students would ultimately be comfortable sharing their ideas about what they honestly thought rather than trying to 
provide a right answer. If this could happen perhaps some real conceptual change could take place.

The Study

Eager to take the plunge, I decided to begin the 2011 school year using strictly modeling instruction. I realized my MS-ASE capstone project could utilize the data that I collected during this time. I had made attempts in the years prior to collect meaningful data related to conceptual change and the effect the bridging analogies could have. The problem was I was without a well researched assessment tool to accurately measure student progress. I attempted to create measures of my own but this proved to be much more difficult than I had anticipated and yielded results that called into question the validity of the assessment tool itself. Fortunately I was reintroduced to the Force Concept Inventory $(\mathrm{FCl})$ during the modeling workshop. I remembered taking the $\mathrm{FCl}$ during my undergraduate freshman physics course. As well researched as the $\mathrm{FCl}$ is, I found it to be the perfect instrument to use for research in my classroom.

I was pleased to find I had unknowingly been transitioning my teaching style toward something similar to modeling in my prior attempts to conduct research in my classroom. The curriculum sequence in modeling instruction might be viewed as a multitude of bridging analogies. The idea of starting with an intuitive context and common sense ideas that can be easily agreed on and then working toward a target concept by the use of bridging is a common theme. Analogies, per se, may not appear 
as often as mental models do in modeling but nevertheless, models and the refinement of these models serve as stepping stones along the path toward a scientifically consistent Newtonian understanding of physics. Therefore there are many similarities between modeling and the use of bridging analogies.

I was very curious to see if incorporating this method would have any measurable impact on my students' learning. During the workshop we read several physics education research articles which published findings for normalized $\mathrm{FCl}$ gains of the students of novice modelers. It seemed like a perfect opportunity for me to see what gains my own students could make. What effect would modeling instruction have on the normalized gains of my students on the Force Concept Inventory? I was also curious to see if the Fall of 2012 physics students, whom I had taught solely using the modeling method in Intro to Physics, would perform differently on the $\mathrm{FCl}$ than those students who had taken a traditional Intro to Physics course or bypassed Intro to Physics altogether. Would taking more modeling courses significantly deepen their conceptual understanding? Perhaps I could learn something about the deeply rooted nature of preconceptions in mechanics by comparing the $\mathrm{FCl}$ results of these two groups.

I was also curious about my students understanding of Newton's Third Law and more specifically Newton's Third Law Force pairs. During my MS-ASE internship experience at MTU, I had performed numerous static bend tests and various other 
strength tests on logs and timbers. In a static bend test, a beam is loaded at the center and the deflection of the board at mid-span is observed under various loads. Correlating the amount of bending in the board or timber to the amount of force being applied was something that I could use in my own classroom with relatively simple lab equipment. Using springs as the objects deforming under loads was another option, but I decided to start with boards. Perhaps this approach would also aid in the discussion of forces exerted by surfaces such as floors, tables and walls.

I planned to scale down the experiment to thin boards so that the force amounts would be easily measured with classroom equipment. This type of investigation also appealed to me since the bending amount and force applied would be a linearly related. The use of "for every" statements would work perfectly in this situation. The "Bendy Board Lab" would ask students to bend various thin boards, like meter sticks, and develop equations to describe bending amount and required force. The bending amount would provide evidence of force being applied and also that the board itself exerted force on whatever was pulling it. In part II of the Bendy Board Lab I asked students to support the ends of the boards so that the boards were on edge and parallel to each other. These boards were positioned across a lab table from each other to allow for string or light rope to be attached at mid-span so that the boards could apply force to each other as the string was shortened. The boards pulling on each other would represent a Newton's Third Law Force Pair (N3LFP. This lab was quite similar in 
structure to some of the bridging analogy demos I had researched and used to a small degree in the past in my classroom.

I wondered what the effects, if any, these Static Bend Labs would have on student learning. How would modeling and bridging analogies involving static bend tests be used to promote student learning of Newton's Third Law? In an attempt to assess their beliefs regarding Newton's Third Law I identified four specific questions on the FCl that dealt specifically with Newton's Third Law. I planned to analyze their performance on these four questions separately in conjunction with their overall $\mathrm{FCl}$ performance. 


\section{Chapter 2 - Literature Review}

Preconceptions abound in high school physics classrooms. "A preconception is a knowledge structure or disposition that a student has prior to a given course." (Camp \& Clement, 2010, p. 6) This fact is not only apparent to physics teachers but has been well documented in many physics education research (PER) studies. "To cope with ordinary experience each of us has developed a loosely organized system of intuitions about how the world works" (Hestenes, 2006, p. 18). Hestenes' choice of the words "loosely organized" should not be overlooked.

I have often observed internal inconsistencies and contradictions in students' belief systems about Newtonian mechanics. Fortunately, "one great strength of Newtonian mechanics is that it is a coherent conceptual system, and this can have as much impact on student learning as it did on scientists adopting the system in the first place" (Hestenes, Wells \& Swackhamer, 1992, p. 150). While a student may have internal inconsistencies within their conceptual framework, the coherence of the concepts can work as a system of checks and balances. The concepts in Newtonian mechanics are very interrelated. Addressing one preconception builds the foundation for other preconceptions to be challenged or confirmed in the future.

“Many preconceptions that pose difficulties are not simply random errors;

rather, they are often reasonable ideas, but based on assumptions that conflict with the 
scientist's view" (Camp \& Clement, 2010, p. 2). Students' ordinary experiences provide them with the "intuitive grounding for CS (commonsense) beliefs about force and motion, which are embedded in natural language and studied in linguistics and PER" (Hestenes, 2006, p. 18). It is not only important to incorporate these ordinary experiences as a means to draw on prior knowledge, but to also beware of the many differing perceptions that students have when recalling these experiences.

The Importance of Student Preconceptions

"Over the last decade, physics education research has established these beliefs play a dominant role in introductory physics. Instruction that does not take them into account is almost totally ineffective, at least for the majority of students" (Hestenes, Wells \& Swackhamer, 1992, p. 141). Of course it is not sufficient to simply be aware of student preconceptions. How we respond to our students' ideas is crucial. Student preconceptions "should be respected as creative constructions of the individual. Under no circumstance should they be criticized as foolish" (Camp \& Clement, 2010, p. 6). In fact, preconceptions can serve as a logical starting point for learning. Camp and Clement (2010) point out that some "preconceptions are intuitions that are in basic agreement with the physicist's views. Here we call these 'anchoring intuitions' and attempt to build on them" (Camp \& Clement, 2010, p. 6). Some student preconceptions might seem like anchoring intuitions for them. It can be challenging for a teacher to affirm only the necessary anchoring intuitions and then allow students to make further 
inquiries into the content. Students often want to memorize rules or laws that can guide their thinking. These laws may be helpful and hold true in many cases. Unfortunately students end up applying rules that they memorize inappropriately or to applying them to contexts that are not appropriate for the rule.

An anchoring intuition can be used as "a rival to a conflicting preconception and eventually predominate as an idea that makes sense in physics" (Camp \& Clement, 2010, p. 2). In my prior attempts to complete the MS-ASE capstone project I discovered the idea of anchoring intuitions and bridging analogies and how they could be used in order to move students" understanding toward a target concept. "Clement has developed an instructional technique called "bridging," which exploits strengths in student intuitions by inducing them to establish conceptual "bridges" between different physical situations, thus sharpening their recognition of similarities and differences" (Hestenes, Wells \& Swackhamer, 1992, p. 151). While attending the modeling workshop in 2011, I commented to the facilitator that I saw a lot of similarities between bridging and modeling. Although the modeling method of instruction involves more than just "bridging", the technique appears repeatedly on many different levels within modeling.

Since students have developed their own understandings of the physical world over many years, their ideas are not easily corrected. "Deeply held conflicting preconceptions are not usually changed by arguments coming solely from an outside authority" (Camp \& Clement, 2010, p. 383). McDermott echoes this idea. "Deep-seated 
difficulties cannot be overcome through assertion by the instructor" (McDermott, 1993, p. 296). As a teacher I often found myself saying things like "I know this sounds very counter-intuitive but...", or "I know you've grown up thinking that...", etc., which did little to bring the students into the discussion. It might be argued that I was an outside authority discrediting the understanding of their own experience. Camp and Clement go on to say that, "Only by coming to understand the various arguments for and against the competing models can students change their conceptions" (Camp \& Clement, 2010, p. 383).

What I witnessed in practicing whiteboard discussions during the modeling workshop seemed to be a helpful approach to encouraging the comparison of various mental models formulated by students. Simply delivering physics concepts to students for mental consumption is strongly discouraged by McDermott. "The trouble with the traditional approach is that it ignores the possibility that the perception of the students may be very different from that of the instructor" (McDermott, 1993, p. 295). The differing perceptions that students have can be much more easily molded in an atmosphere that encourages the comparison of student ideas. Research also indicates that "in order to successfully develop conceptual understandings in science, learners need to be able to reflect on and discuss their understandings of scientific concepts as they are developing them" (R. K. Coll. et al., 2005, p.194). 
Class discussions can easily become confusing and unfocused if students are not given specific direction or content to discuss. Using data collected from a lab investigation is one very useful way to establishing a physical context and focusing a class discussion. "Explicit reference to evidence to support such arguments is intended to ensure that such discussions are focused towards clear conceptual outcomes" (R. K. Coll. et al. p192). In this way the instructor can use the lab investigations to not only enhance the class discussion but also facilitate learning of specific content linked to a specific lab investigation. Well designed or thoughtful questions are critical to the success of Socratic questioning techniques in the classroom. Similarly, "the design of the task will be critical to the successful realization of these goals as focused conceptual development" (R. K. Coll. et al. p192) when it comes to lab investigations or activities. The instructor is met with challenges in this area. Student activities must be designed in a very intentional way and sequenced in a way to promote conceptual change. It is also important to use activities that address a limited amount of concepts so that students can spend adequate time developing their understanding of each concept.

\section{Accommodation versus Assimilation}

As an instructor it is very tempting to aggressively challenge each misconception by telling students why their theory doesn't work. However, this undermines the inquiry process. If we truly want our students to alter their beliefs about the physics 
they are attempting to describe, it is crucial that the concepts find root in a framework that is coherent and is strengthened with the addition of these beliefs.

According to Piaget "there are two kinds of learning, which he calls assimilation and accommodation. Assimilation is the integration of information into an existing schema. Accommodation is the modification of a schema to be consistent with new information. Under appropriate conditions schema change occurs spontaneously by a process called equilibration or self-regulation, which involves a feedback loop relating an action to its consequences" (Hestenes, 1987, p. 22).

Accommodation appears to be the ultimate goal in physics education. Students will not be able to build on a Newtonian understanding of mechanics unless these schema changes occur. Hestenes, Wells \& Swackhamer echo this sentiment. Misconceptions can be successfully overcome only when something better (namely, Newtonian concepts) is available to replace them. (Hestenes, Wells \& Swackhamer, 1992, p. 150) Camp and Clement (2010) state that misconceptions should not be viewed as something that needs to be "stamped out". But in order to understand Newtonian mechanics, students must become aware of contexts where intuitive misconceptions conflict with Newtonian models. (Camp \& Clement, 2010, p. 6) This is where the use of models and activities is very useful. However, to further complicate the issue, the instructor also has to remember that many misconceptions are related. As a reminder of this Camp and Clement "warn against a piecemeal approach directed at each misconception separately" (Camp \& Clement, 2010, p. 6). 
The Modeling Method of Instruction

Modeling Instruction is designed to help students to build mental models that enhance their understanding of physics. Hestenes (1987) highlights four main components of the modeling cycle. In the explicit formulation stage students draw on prior knowledge and consider CS beliefs related to the content. Next students check for external validity by considering empirical evidence collected in lab investigations. Checking for internal validity can be accomplished next by further analyzing the results or investigating further. Finally, "students should be induced to compare and decide between conflicting beliefs, belief systems, including, of course, relevant scientific beliefs" (Hestenes, 1987, p. 24). Ideally the class can come to a consensus that aligns with scientific beliefs. Depending on the class, further questioning or investigating may be needed if misconceptions persist.

On a more practical level, Hestenes has identified the three primary strategies or techniques that are employed throughout the modeling cycle.

- "Modeling activities that systematically engage students in developing models and providing their own explanations for basic physical phenomena,

- Modeling discourse (centered on visual representations of the models) to engage students in articulating their explanations and comparing them with Newtonian concepts,

- Modeling concepts and tools (such as graphs, diagrams and equations) to help students simplify and clarify their models and explanations" (Hestenes, 2006, p. 18). 
"Thus, in normal science the accommodation process is continually operating to reconcile discrepancies between scientific models and empirical data" (Hestenes, 1987, p. 22). The level of student engagement and the emphasis on physical context were themes that appeared repeatedly during the Modeling workshop. According to McDermott, "development of a functional understanding cannot take place unless students themselves go through the reasoning involved in the development and application of concepts" (McDermott, 1993, p. 298). During the lab investigations instructors can probe the thinking of students while they are working using Socratic questioning. However, classroom discourse can also be more efficient since a larger amount of students can be engaged in the discussion. The use of modeling tools such as graphs, diagrams and equations are very useful in focusing the discussion and allowing students to make connections between the information that each tool conveys. Verbally describing the mathematical relationships using "for every" statements was another related modeling tool. "For every" statements will be discussed in more detail later in this chapter.

Another theme of modeling instruction is the idea of multiple representations. The concept of acceleration, for example, can be approached by observing a ball rolling down a hill. Representing this motion can be done by drawing a motion map for the ball, plotting its position versus time, sketching a velocity versus time graph, writing an equation, or writing a "for every" statement. These multiple representations show 
various aspects of the motion in unique ways. It is very enriching for students to have multiple ways of communicating their ideas. "Moreover, to be able to transfer a skill learned in one context to another, students need multiple opportunities to use that same skill in different contexts" (McDermott, 1993, p. 298). Using a variety of modeling tools and a variety of lab investigations provides students with practice in transferring their skills.

One inherent challenge in modeling instruction is allowing students to formulate their understandings incrementally. As previously discussed, it may be tempting to correct student explanations that stray from a Newtonian understanding. "Students must construct, evaluate, and improve their models several times, since they rarely construct the correct model on the first try, even with the benefit of a 'clear and complete' exposition in lecture form" (Camp \& Clement, 2010, p. 383). Students will inevitably present differing mental models and students may even claim to be more confused by the way that another student has explained something. However, in my experience, the best discussions result from students passionately defending their viewpoints and ways of understanding the concepts. "In a classroom discussion led by a skillful teacher, students evaluate assertions and explanations of their peers, and actively try to make sense" of the concepts (Camp \& Clement, 2010, p. 383).

The advantage of the modeling method in a classroom discussion is the availability of many tools to enhance the discussion. These modeling tools or multiple 
representations have largely been constructed by the students themselves. Allowing students to defend their viewpoints by referring to their own data or observations could be seen as a much more inviting approach to students who do not want to be corrected by the instructor. "This contrasts with passively accepting ideas on the basis of authority" (Camp \& Clement, 2010, p. 383). Students are able to make connections to results that have context and meaning since they were the ones who collected the data in the first place. "This active "self evaluation" is extremely important in areas such as science where students are likely to have or develop alternative conceptions due to the complexity or counterintuitive nature of the material" (Camp \& Clement, 2010, p. 383). Creating an atmosphere that is conducive to modeling discourse is not an easy task. However, it is perhaps one of the best ways to address these complex and deeply rooted preconceptions that students enter the classroom with. Perhaps it is also more efficient than repeated traditional delivery of information that all too often fails to challenge students in constructing their own scientific understanding.

\section{Force Preconceptions}

The word "force" is used often in everyday language and its meaning often depends on its context. In physics there may be various types of forces but they can all be characterized and some sort of push or pull. The common sense (CS) idea of force usually has to do with a person or machine actively engaged in some sort of motion and quite often viewed as causing acceleration. "The CS prototype for force is human action 
on an object. Consequently, students don't recognize constraints on motion like walls and floors as due to contact forces" (Hestenes, 2006, pp. 19). Students often view these examples as instances where an object just "got in the way" or "absorbed the impact" of something else. Similarly, they do not see "resistance to movement" from a surrounding fluid medium, or from rubbing at surfaces, as a force. (Arons, 1997, p. 75) The situation is probably even more strange from the students' perspective if the objects are simply at rest. It seems like "nothing is happening". Teachers try to activate student intuition by emphasizing the 'force is a push or a pull,' without realizing that unqualified application of this metaphor excludes passive forces" (Hestenes, 2006, pp. 19). It is important for students to recognize forces in a variety of contexts and to be able to see the commonalities from one situation to another, whether they seem to passive or active situations.

While discussing modeling instruction, Hestenes (2006) refers to Clement and Camp's instructional strategies. These strategies engage "students in constructing a series of 'bridging analogies' to link, for example, the unproblematic case of a person pressing on a spring to the problematic case of a book resting on a table" (Hestenes, 2006, pp. 19). The assumption is that being able to observe obvious deformation in a material such a spring or board will trigger the intuition of students. "To arrive at force universality on their own, students need to develop intuition to recognize forces in any instance of physical contact" (Hestenes, 2006, pp. 19). The hope is that students will be 
able to relate forces with the visual evidence for forces. The case of a book resting on a table becomes problematic due to the microscopic amount visual evidence or bending that occurs. "Because they are aware of the deformation, they can be led to admit that the bed, sofa, easy chair exert an upward force on the sitter, but they regard apparently 'rigid' objects as being qualitatively different and do not readily visualize decreasing but nonzero, deformation as rigidity increases" (Arons, 1997, p. 75). Building logical bridges toward this target case of rigid objects exerting forces can be achieved with the use of other models such as a spring-like lattice model to represent atoms bonded together in a solid. (Camp \& Clement, 2010, p. 23)

\section{Newton's Third Law}

Newton's third law may be one of the most frequently quoted laws of physics. Perhaps it has a somewhat poetic ring to it that makes it easy to remember. In any case, the related physics concepts are very commonly misunderstood by many students. Arnold Arons provides a rather scathing commentary regarding the traditional phrasing of Newton's Third Law. "The old, conventional jargon 'for every action there is an equal and opposite reaction' has always been gibberish to the majority of students and, fortunately, many authors are abandoning it" (Arons, 1997, p. 76). He proposes a definition such as "if one object exerts force on a second, the second exerts an equal and opposite force on the first" - or some other, equally simple and straightforward form" (Arons, 1997, p. 76). Although the poetic ring may be missing in this formulation, 
the ambiguity of the words "action" and "reaction" have been replaced with much more meaningful terms. Provided that the phrase "exerts force" can be clearly understood by students, this type of wording can actually be applied by students to the analysis of forces acting between objects.

Having said this, there are other preconceptions that will surface even in the presence of such a "clear" definition. "Indeed, [students] often confuse action/reaction pairs with the superposition of oppositely directed forces on a single object. This is another example of poorly differentiated concepts so typical of commonsense thinking" (Hestenes, Wells \& Swackhamer, 1992, p. 144). This is quite apparent to the instructor when students search for Newton's Third Law Force Pairs (N3LFPs) on a single force diagram, drawn for forces acting on that object only. Arons concurs by stating that "students, even when repeating the words correctly, do not do so with the clear realization that one is talking about two different forces, each acting on a different body. They need extended help in building this realization and making it explicit in diagrams and in their own words" (Arons, 1997, p. 76).

The fact that N3LFPs are equal in magnitude and opposite in direction also presents a challenge to students.

\footnotetext{
"Students often interpret the term 'interaction' by a 'conflict metaphor'. They see an interaction as a "struggle between opposing forces". It follows from the metaphor that "victory belongs to the stronger." Hence, students find Newton's Third Law unreasonable, and they prefer some version of the dominance
} 
principle: In a conflict, the "more forceful" exerts the greater force" (Hestenes, Wells \& Swackhamer, 1992, pp. 143-144).

These types of CS metaphors for forces and interactions work very well in everyday examples that involve the military, governments, sports teams or perhaps families. It is no wonder that students find it confusing to imagine N3LFPs. They need new physical contexts to draw observations from and analyze. Fortunately many such interactions can be recreated in the classroom. "Because of its strong metaphorical base, the dominance principle (though it is seldom clearly articulated) is so natural to students that it is one of the last misconceptions to be overcome in the transition to Newtonian thinking" (Hestenes, Wells \& Swackhamer, 1992, p. 144). Clinging to the dominance principle is also not unique to just high school students. "Indeed it is still to be found in some physics graduate students" (Hestenes, Wells \& Swackhamer, 1992, p. 144).

\section{The Force Concept Inventory}

"The Force Concept Inventory (FCI) is a unique kind of 'test' designed to assess student understanding of the most basic concepts in Newtonian physics. It can be used for several different purposes, but the most important one is to evaluate the effectiveness of instruction. For that purpose the $\mathrm{FCl}$ is probably the most widely used instrument in physics education today" (Hestenes \& Halloun, 1995, p. 502). 
Since it was first published in 1992 "the test has been carefully examined by many physics professors. Suggestions have been made to improve the wording or diagrams for a few of the questions, but there has been no serious question as to which is the closest to a Newtonian choice on any of them" (Hestenes \& Halloun, 1995, p. 502). I recall taking the $\mathrm{FCl}$ as a freshman at a Michigan Technological University during my first introductory physics lab course. As I mentioned earlier, I took it again during the Modeling workshop. Taking the $\mathrm{FCl}$ as a posttest after the workshop was very interesting. I found myself thinking about how my students might have a similar experience.

The $\mathrm{FCl}$ has been used extensively to probe student understanding. One common concern with $\mathrm{FCl}$ is whether administering the test as a graded or ungraded assignment would effect results. The other obvious concern with using the test as a pretest and posttest is whether seeing the test again would effect student performance. Henderson (2002) reported that "because of the large number of students who take the $\mathrm{FCl}$ each year at the University of Minnesota, we have been able to address some common concerns about using the FCl" (Henderson, 2002, p. 546). He concluded that for students at the University of Minnesota there was little difference between $\mathrm{FCl}$ scores when the test is given graded versus not graded. Giving the $\mathrm{FCl}$ as a pre-test also did not affect the post-test results. (Henderson, 2002, p. 546) These conclusions were 
encouraging to me since I was quickly convinced that using the $\mathrm{FCl}$ would be a good way to assess my students' Newtonian understanding.

"From a physics perspective, each $\mathrm{FCl}$ question requires the student to discriminate a Newtonian answer from four alternative non-Newtonian responses" (Hestenes \& Halloun, 1995, p. 505). "The Inventory, therefore, is not a test of intelligence; it is a probe of belief systems" (Hestenes, Wells \& Swackhamer, 1992, p. 142). It is useful not only in measuring student achievement in Newtonian mechanics but also highlights popular misconceptions that students enter a course with and whether or not these misconceptions persist. Teachers often view many of the questions as quite simple and expect their students to fare well. "This makes a negative (non-Newtonian) response highly informative. In shock, many a physics teacher has exclaimed "How could my students miss that?" (Hestenes \& Halloun, 1995, p. 505) These student errors are usually not just careless mistakes. "Extensive interviews with students by many investigators have repeatedly confirmed that a negative response is nearly always a reliable indicator of some deficiency in the student's understanding of Newtonian concepts" (Hestenes \& Halloun, 1995, p. 505).

Hestenes (2006) reports that from 1995-98 FCl pretest data was collected from 7500 students during the Modeling Instruction Project. The pretest mean score from the data collected was $26 \%$. This is "well below the $60 \%$ score which, for empirical reasons, can be regarded as a threshold in the understanding of Newtonian mechanics" 
(Hestenes, 2006, pp. 16-17). According to Hestenes and Halloun's extensive research they consider "an FCl score of $85 \%$ as the Newtonian Mastery Threshold" (Hestenes \& Halloun, 1995, p. 505). Using traditional instruction techniques, teachers participating in the study found that their students' posttest mean about $42 \%$ prior to their participation in the study. After one year of modeling instruction the $\mathrm{FCl}$ posttest scores for students of these "novice modelers", as they are referred to in the literature, rose to $52 \%$. Interestingly enough these students had also scored $26 \%$ on the pretest. (Hestenes, 2006, p. 17)

"The total FCl score has proved to be a useful measure for comparing different courses and teaching methods, and a large database will therefore facilitate comparisons throughout the teaching community" (Hestenes \& Halloun, 1995, p. 505). This is a convenient way for novice modelers, to gauge the performance of their students and their own instructional performance. "The total $\mathrm{FCl}$ score is the most reliable single index of student understanding, because it measures coherence across all dimensions of the Newtonian force concept" (Hestenes \& Halloun, 1995, p. 505).

Interpreting $\mathrm{FCl}$ pre and posttest scores is one way of measuring student learning. However, students have varying abilities and different prior knowledge. To address this concern normalized gains $\langle\mathrm{g}\rangle$ are calculated as, $\langle\mathrm{g}\rangle=(\%<$ posttest $\rangle$ $\%<$ pretest $>) /(100-\%<$ pretest $>$ ) $($ Hake, 2002, p. 3) This essentially levels the playing field. The Hake gain $\langle\mathrm{g}\rangle$ is basically a ratio of how much improvement a student makes 
compared to how much they potentially could have improved. Hake (1998) published $\mathrm{FCl}$ gains in a study comparing traditional and what he called interactive engagement courses.

"Fourteen traditional $(\mathrm{T})$ courses ( $\mathrm{N}=2084)$ which made little or not use of interactive-engagement (IE) methods achieved an average gain $\langle<\mathrm{g}\rangle>14 \mathrm{~T}=.23+/$ 0.04 . In sharp contrast, $48 \mathrm{IE}$ courses ( $\mathrm{N}=4458$ ) which made substantial use of IE methods achieved an average gain $\langle\langle\mathrm{g}\rangle>48 \mathrm{IE}=0.48+/-0.14$. It is extremely unlikely that systematic errors play a significant role in the nearly two-standarddeviation difference in the normalized gains of the T and IE courses" (Hake, 1998, p. 71).

While interactive engagement results in Hake's (1998) were not limited to only modeling courses, the structure of the IE courses that were not specifically modeling courses employed methods that were very similar to modeling instruction. The study highlights the sharp contrast between the learning gains made by students taught using traditional methods and those taught using more student centered pedagogies.

"For every" statements and the problem with "per"

One modeling tool that was used often during the 2011 Modeling workshop was the use of "for every" statements. These statements were used most effectively to describe linear relationships. "For every one second the battery buggy moves $43 \mathrm{~cm}$ forward" is an example of a "for every" statement that might be written to describe the results of a constant velocity battery buggy lab. A "for every" statement challenges students to extract more meaning from the mathematical equations that they have 
written. These equations are often a result of performing a linear regression on a set of data gathered during a lab that has been entered into a spreadsheet. Students are then required to replace " $x$ " and " $y$ " with variables that correlate to their physical meaning. In my experience ratios or rates such as $\mathrm{m} / \mathrm{s}, \mathrm{m} / \mathrm{s} / \mathrm{s}, \mathrm{N} / \mathrm{m}, \mathrm{N} / \mathrm{kg}$, etc., are often very difficult for students to comprehend in a way that allows them to use these types of quantities in meaningful ways. Arnold Arons (1997) has a lot to say about ratios and the use of the word "per". "If a teacher accepts casual use of the word "per" - particularly the incorrect and meaningless "mass per volume,"... he or she falls into a trap" (Arons, 1997, p. 7). This I found hard to believe at first during the workshop, but it soon became very clear to me that "per" means very little to most of us.

"Even though it contains only three letters, 'per' is a technical term, and very few of those students who are having trouble with arithmetical reasoning know what it means. They inject it into a response only because they have a vague memory that "per" frequently turns up for some obscure reason in division, but they do not explicitly translate it into simpler words such as 'in', 'for each,' 'corresponds to,' 'goes with,' 'combines with,' 'is associated with.'” (Arons, 1997, p. 7)

In 1981, Clement, Lochhead and Monk published their results of a study related to student interpretations of equations and ratios. Students were asked to write an equation to represent the statement: "There are six times as many students as professors at this university. Use $\mathrm{S}$ for the number of students and $\mathrm{P}$ for the number of professors" (Clement, Lochhead \& Monk, 1981, p. 288). At first glance the question seems trivial. However, "on a written test with 150 calculus-level students, $37 \%$ missed 
this problem and two-thirds of the errors took the form of reversal of variables such as 6S=P" (Clement, Lochhead \& Monk, 1981, p. 288). The error rate was $20 \%$ higher among non-science majors enrolled in a college algebra course. (Clement, Lochhead \& Monk, 1981, p. 288)

Arons (1997) discusses the results of this study. "Some students appeared to use a word order matching strategy by simply writing down the symbols 6S=P" (Arons, 1997, p17). In another approach students even drew pictures "showing six S's and one P" (Arons, 1997, p17). They still believed, however, that the relationship was to be represented by $6 \mathrm{~S}=\mathrm{P}$, apparently using the expression $6 \mathrm{~S}$ to indicate the larger group and $\mathrm{P}$ to indicate the smaller" (Arons, 1997, p17). It appears as though these students were confusing variables with units. "They did not understand S as a variable representing the number of students but rather treated it as a label or unit attached to the number 6 as in 6 feet or 6 meters" (Arons, 1997, p17).

Students who successfully translated the practical situation into a mathematical equation used a process altogether different from the erroneous approaches previously discussed. "In the students-and-professors problem, the number $\mathrm{S}$ is seen as bigger than $\mathrm{P}$; therefore, the number $\mathrm{P}$ must be operated on by multiplication by 6 to produce a number that is the same as S" (Clement, Lochhead \& Monk, 1981, p. 289). This type of thinking process is much more complicated and lends itself to the use of multiple modeling tools rather than just simple order matching. "This is a lot to squeeze into the 
sentence $6 \mathrm{P}=\mathrm{S}$, but it is exactly what is required in order to understand the meaning of the simplest algebraic equations" (Clement, Lochhead \& Monk, 1981, p. 289). I realized that if a simple situation such as this could present such a challenge to higher level students, my students would definitely need a lot of practice in the area of interpreting equations. Fortunately multiple representations and the use of "for every" statements can provide a means for students to develop these skills. For example, a correct interpretation of the question previously discussed could be; "for every one professor there are six students". Perhaps using hypothetical data that would realistically represent this situation would be a good starting point for a student trying to write an equation to describe the relationship between $\mathrm{S}$ and $\mathrm{P}$. This further emphasizes the importance of lab investigations that involve data collection and analysis of the data. Proportional reasoning skills can be practiced if the right questions are asked of students while analyzing the data. The need for physical contexts from which to draw data and the need to ultimately give meaning to the equations that describe the data is echoed in the following statement.

\begin{abstract}
"The reversal error appears to be due not to simply carelessness but rather to a self-generated, stable, and persistent misconception concerning the meaning of variables and equations." Simply manipulating equations may not address this misconception "since these techniques usually do not require one to understand the meaning of an equation" (Clement, Lochhead \& Monk, 1981, p. 289).
\end{abstract}

Having multiple opportunities to practice translating practical situations to mathematical equations is necessary. Transferring these skills to new contexts would be 
something that students would most likely struggle with from time to time. My hope was that the seeing a variety of linear relationships and "for every" statements during the first few weeks of the course, my students would be familiar with these modeling tools and view them more as tools rather than simply demands of the instructor. I planned to use "for every" statements as an integral part of as many lab activities as possible. This will be described in further detail in the next chapter. 


\section{Chapter 3 - The Study}

The classes that I teach at Spring Lake High School pertaining to this study are Intro to Physics and Physics. Intro to Physics is typically taken during the sophomore year and is a required science class. However, the policy at our school was that students could test out of Intro to Physics or bypass it based on their previous math and science grades. The pros and cons of this policy of students bypassing Intro to Physics could definitely be debated. As I have already mentioned, misconceptions in physics are widespread and deeply rooted. There is no guarantee that students who perform well in math and science courses prior to physics are necessarily more accomplished Newtonian thinkers. I was confident that giving the $\mathrm{FCl}$ as a pretest would provide evidence of this.

Spring Lake High School follows a 12-week trimester schedule. This has been the case for my entire teaching career there, which began in 2003. Physics A runs for one trimester as does Physics B. Intro to Physics is a single trimester course as well. Starting in $2011 \mathrm{I}$ administered the $\mathrm{FCl}$ as an unannounced pretest in each of my Intro to Physics and Physics classes. As recommended, I allowed 30 minutes for students to complete the test. The pretest was given at the beginning of the 12 week trimester and another toward the end of trimester. In Physics A an unannounced posttest was given after we had studied most of the mechanics material. However, in 2011 projectile motion had not been covered in its entirety in Physics A by the time the posttest was given. To 
ensure consistency, I kept this in mind in 2012 and administered the posttest after the same amount of content had been covered in Physics $A$.

During 2011-12, FCl data was collected from 188 Intro to Physics students, 38 Physics A students and 30 Physics B students. During the first two trimesters of the 2012-13 school year data from an additional 123 Intro to Physics students, 62 Physics A students and 14 Physics B students was added to the study. The small amount of students included in the 2012-13 Physics B results is due to the trimester schedule. The majority of the 2012-13 Physics B students enrolled in Physics B in the spring of 2013 due to limited course offerings in other subjects. More data would have been available had this study been extended to the end of the 2012-13 school year.

\section{$\mathrm{FCl}$ Gains}

In 2011, my Physics A students had either taken a traditional Intro to Physics course or bypassed Intro to Physics. This group will be referred to as Group A $(n=38)$. I also planned to track the performance of the students who had enrolled in the modeling style Intro to Physics in 2011 and who also went on to enroll in Physics A in 2012. This group will be referred to as Group B $(\mathrm{n}=38)$. I planned to compare the $\mathrm{FCl}$ performance of Group B to a third group, Group C ( $n=24)$, who enrolled in Physics A in 2012 after either taking traditional Intro to Physics in 2010 or bypassing Intro to Physics. I expected the students in Group B perform better in physics compared to Group C. In 2011 I was not able to separate my physics students into two groups since none of the 
students had taken a modeling Intro to Physics course. However, I was curious to compare $\mathrm{FCl}$ gains in 2011 to $\mathrm{FCl}$ gains 2012.

Since the modeling group, Group $\mathrm{B}$, would take the $\mathrm{FCl}$ a total of four times during the two year span while Group A and Group C would only take one pretest and one posttest I was initially concerned. However, the previously discussed in Henderson's study at the University of Minnesota, giving the $\mathrm{FCl}$ as a pretest did not significantly affect posttest performance. The fact that the Intro to Physics $\mathrm{FCl}$ posttest and the Physics A pretest were given roughly a year apart also set my mind at ease. I was also careful not to teach to the test. I never used $\mathrm{FCl}$ questions in class and was even careful to not set up demonstrations in class that would look suspiciously familiar to questions on the $\mathrm{FCl}$.

As suggested by our facilitators during the modeling workshop, I administered the pretest and posttest unannounced. I wanted to know what students really had comprehended and stored in their long-term memory. I didn't want to skew the results by giving them any advance warning or any special review time for it. Invariably high school students might be prone to complain or not give their best effort under these circumstances but I explained to them that I was not grading their performance and simply requested and urged them to try their very best and to take pride in their work.

In general I would say that a large majority of the students gave a decent effort on the pretest and posttests based on the number of students who worked for nearly 
the full 30 minutes on the test. Others who have given the $\mathrm{FCl}$ have certainly faced the same challenge of motivating the students to give their best effort. Henderson's conclusion (Henderson 2002) about graded versus non-graded FCl results being very similar also gave me confidence that a grade incentive would be unnecessary. Giving the $\mathrm{FCl}$ pretest and posttest also fit well into the normal routine of Spring Lake High School. Our principal required us to administer a pretest and posttest in each of our classes. Since the testing was a district requirement I did not request permission from the students to partake in the study. Their results would remain anonymous and the study itself did not require them to do anything differently than they would have done without the study. I was simply implementing modeling as a teaching method and using an appropriate assessment to measure their learning of Newtonian mechanics.

Group B and Group C were naturally delineated due to the circumstances of my switch to modeling instruction in 2011. Therefore student performance would not be affected by a particular student group feeling like they were intentionally taught in a different way to achieve specific research results. Had the two groups of students been taught using different methods during the same school year, perhaps there would have been more room for concern. In 2012, I fortunately had a large amount of students in traditional group, Group C, and the modeling group, Group B.

What effect would modeling instruction have on the normalized gains of my students as measured by the Force Concept Inventory? I was also curious to see if the 
modeling group would perform better on the traditional group. If this were to happen, it would support the hypothesis that the persistent misconceptions in mechanics among my students could be more effectively addressed using a modeling method of instruction. I also planned to include the $\mathrm{FCl}$ results of 188 Intro to Physics students I taught using the modeling method during the 2011-2012 school year.

\section{Bendy Board Labs}

During the 2012-13 school year I implemented the Bendy Board Lab which was specifically designed to address some of the Newton's Third Law misconceptions that were discussed earlier. In the first part of the Bendy Board Lab students investigated how much force was required to bend a board a certain distance. I suggested they measure deflection, or bend amount, in $\mathrm{cm}$. These were pine boards that were a little over 1 " wide and less than $1 / 4$ " thick. C-clamps were positioned $95 \mathrm{~cm}$ apart on the end of a lab table to provide supports on each end. A force sensor or spring scale could then be attached to the board at mid-span with a loop of string as shown in Figure 1. A ruler was also taped to the table directly below the board at mid-span in order to accurately measure deflection. Measuring force in Newtons was well established by this point. Students would then pull on the force sensor a certain amount while the deflection and force amounts were recorded. I expected the students to find fairly linear relationships between the amount of bend and the amount of force required to produce the bend. 


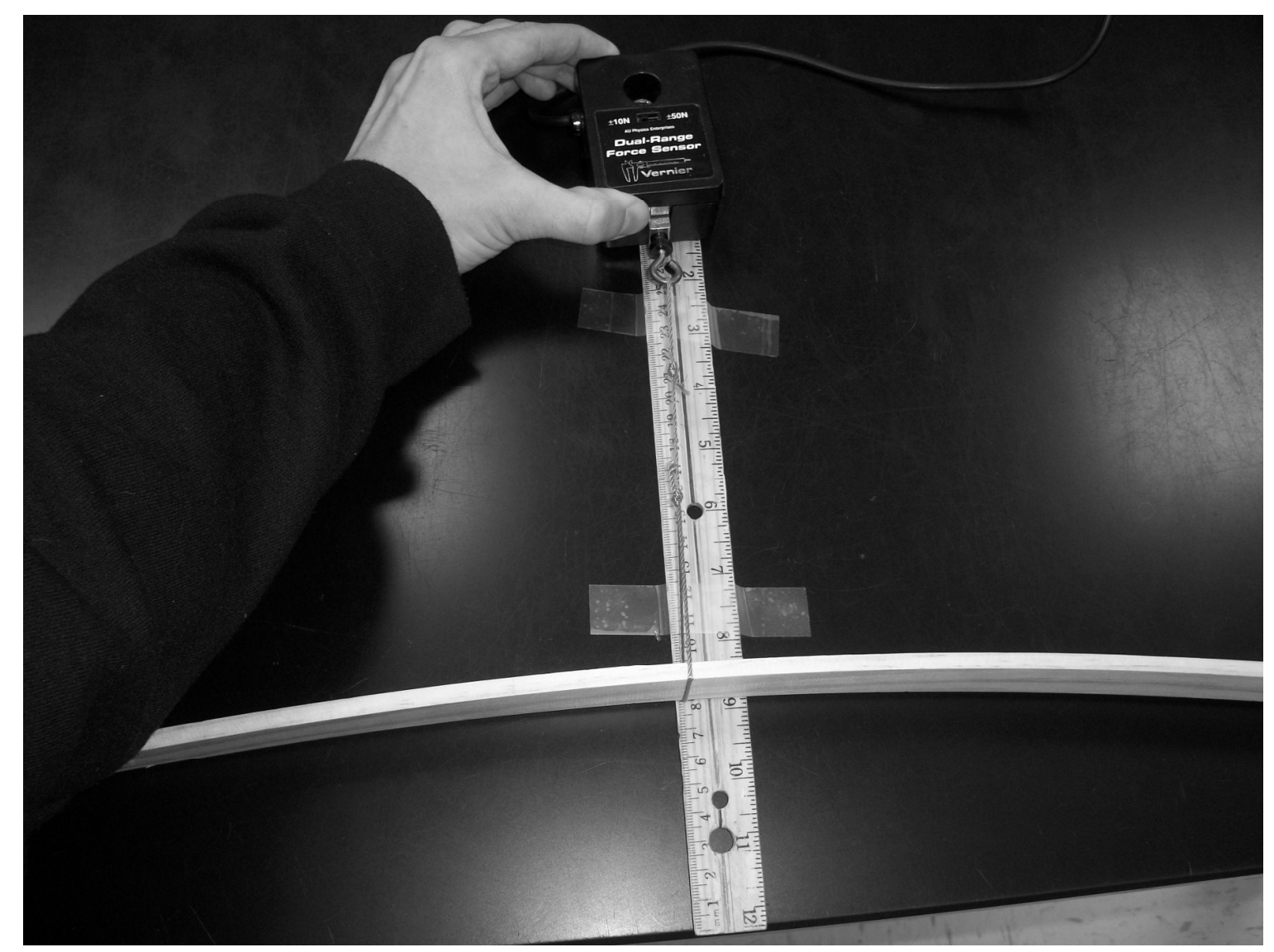

FIGURE 1. - Top view of Bendy Board Lab 1

They repeated the experiment with a wooden meter stick made of stronger wood for which I expected students to measure larger amounts of force for given deflection amounts. Once the data was collected students graphed the bending amount versus force required. Using computer software the students entered the data, performed a linear fit and found the equation of the trend line for each set of data. The equation was then written using variables that represented the bending amount and the force required. Finally a "for every" statement was written for each equation. 


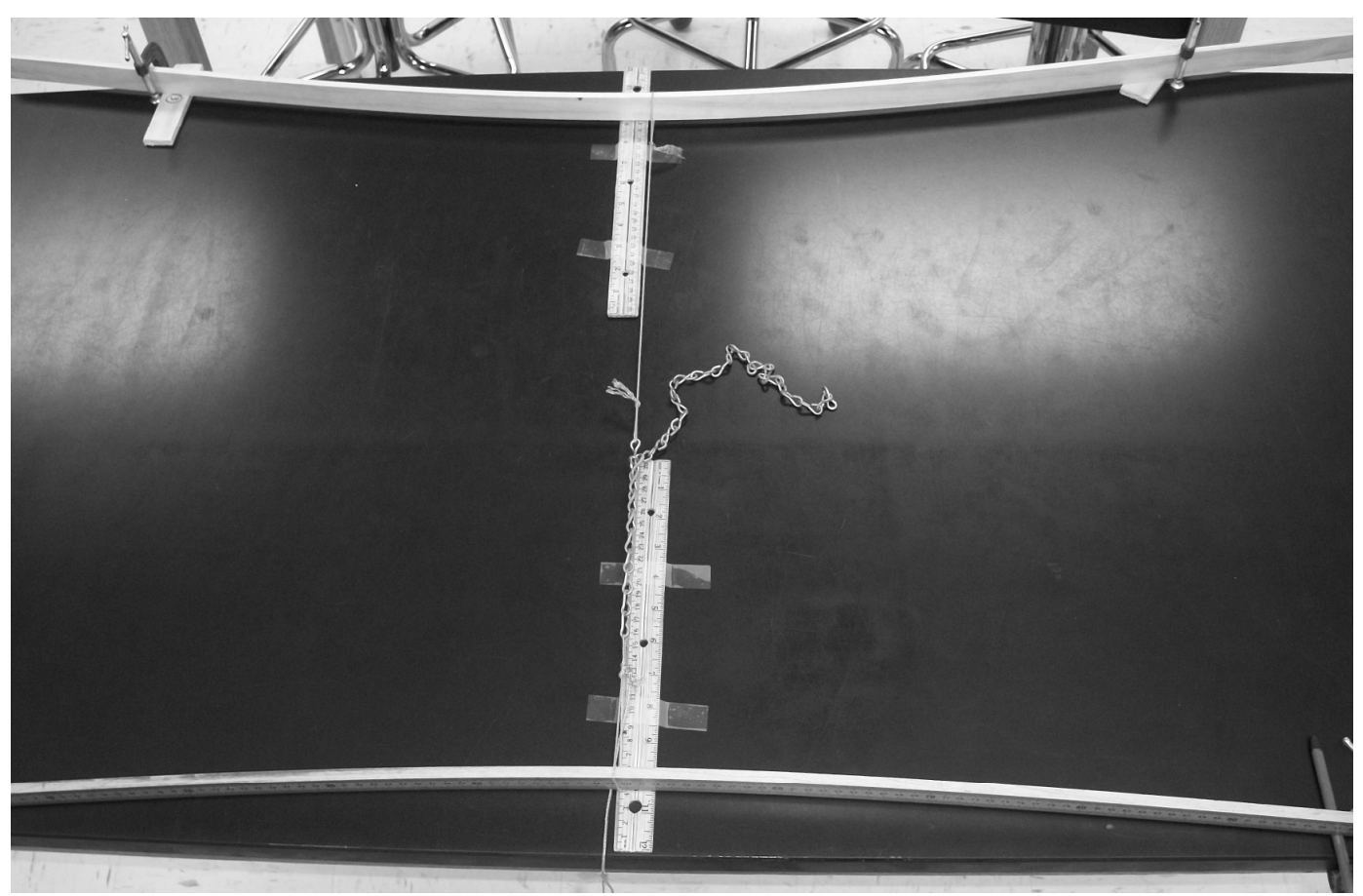

Figure 2 - Top view of Bendy Board Lab Part 2

In the second part of the Bendy Board Lab students set up the meter stick

bending lab apparatus on one side of the lab table and the pine board on the opposite side (see Fig.2-4). Next, they connected the boards with a short section of chain attached to the mid-span of one board and a small metal hook attached to the other board. By moving the hook further up the chain, students could incrementally shorten the length of the connecting chain and string between the boards. The students were then to investigate how the bending amount of one board compared to the bending amount of the other board as the boards applied force, or pulled on each other. After collecting the data a similar analysis of graphing, finding an equation for the trend line and writing a "for every" statement was done. 


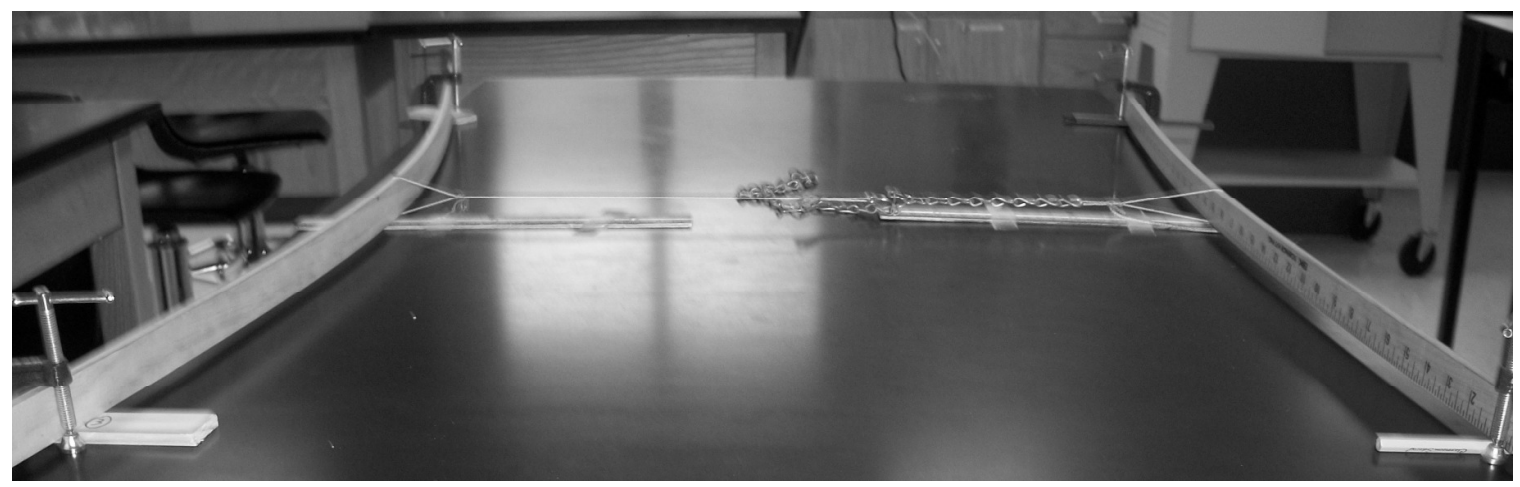

Figure 3 - Side View of Bendy Board Lab Part 2

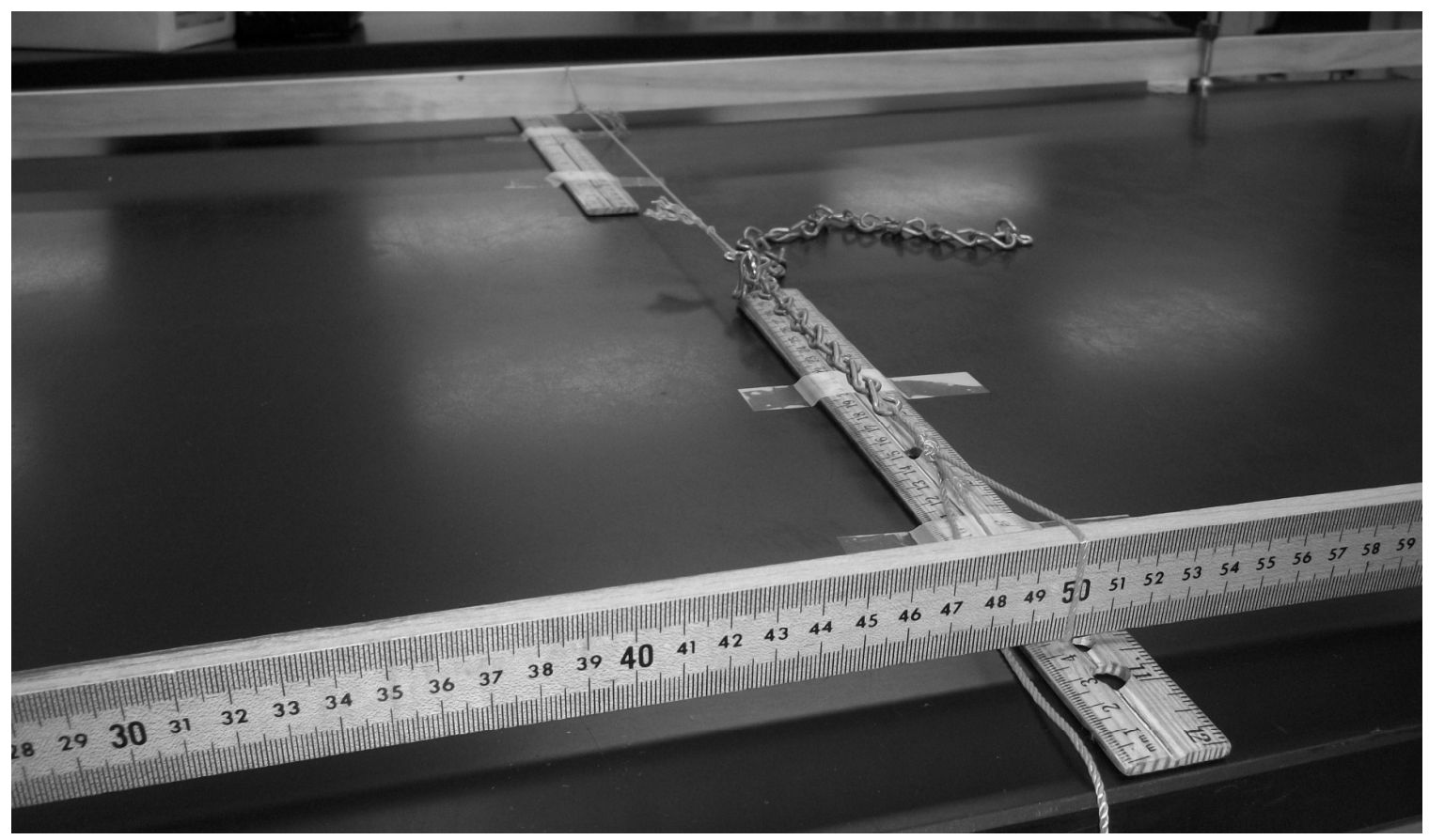

Figure 4-Closer View of Bendy Board Lab Part 2. The connecting chain and hook mechanism made adjusting the length of the connecting string a quick process.

\section{Post-Lab Analysis}

During the class whiteboard post-lab discussion, my goal was for students to determine what the slope of each line they graphed meant in Part 1. I hoped that they could describe the slope as indicating how strong the board was and that it was a 
representative of the ratio of the force to amount of deflection. More specifically I intended for them to be able to make a "for every" statement such as; "for every centimeter of bending, 3.2 Newtons of force was required." In Part 2 the "for every" statements would be worded something like; "for every $\mathrm{cm}$ that the meter stick bent, the board bent $2.4 \mathrm{~cm}$. This ratio of bending amounts was intended for them to relate to the relative amounts of force required to bend each board a given amount.

To conclude Part 2 of the Lab, I planned to have each group use the force equations they had written for each board and substitute realistic deflection amounts into the equations. The groups would have to keep in mind how much one board bent compared to the other. This would determine what realistic deflection amounts were substituted into the equations. For groups that collected quite linear data, my hope was that it would become quite clear that the forces each board applied to the other were equal, or very close to equal. For example, if the bending ratio of two boards was 2:1 then the strength ratios would theoretically be $1: 2$. Simply stated, a board that bent twice as easily would be half as strong, or require half as much force to bend a given amount.

During the winter of 2013, I also added a similar lab called the Spring Lab. The same analysis was done, as with the boards, but instead of measuring the amount of bending, the amount of additional stretching, $\Delta x$, was measured. Understanding the behavior of a spring under certain forces also helps students to understand how a spring 
scale works. Push-pull style spring scales also work to show spring compression due to a push, rather than always having to pull on the spring scale. This would serve as a helpful link to situations where objects are pushing on each other.

Perhaps this was a very round-about way of addressing N3LFPs, but I wanted students to carefully analyze what was happening between objects when they push on each other. I also viewed visual evidence, such as bending, as very important to their understanding of forces in other contexts. As previously discussed, evidence of bending, stretching or compressing can serve as an anchor or a bridge toward more problematic cases such as the ground, floor or table actually pushing up on an object that is resting on it. I hoped that this lab would also serve as an accessible context for discussing forces on accelerating objects, such as a person in an elevator, or a collision of involving two objects.

In this portion of the study I wished to answer my final question. How could modeling and bridging analogies involving static bend tests be used to promote student learning of Newton's Third Law? To measure gains in their understanding of N3LFPs I identified four questions on the $\mathrm{FCl}$ that deal most directly with Newton's Third Law. I planned to analyze the performance on these four questions separately by extracting the results from the $\mathrm{FCl}$ pretest and posttest. 


\section{Chapter 4 - Results}

Implementing the modeling method of instruction was a very interesting and challenging experience. I found that I spent much of my time designing the lab investigations to meet the needs of my students, adjusting the sequence slightly and continually trying to improve as a modeler. Whiteboard discussions were challenging to facilitate. There were times where I was too impatient and interjected too early. It is always challenging for the instructor to trust the process and to allow students to challenge misconceptions on their own terms. I found that students debated their ideas passionately and uncovered many misconceptions when they were properly engaged in the whiteboard discussions. I also observed that some students were more resistant to the idea of the instructor not answering their questions. However, they began to adjust to the modeling method as the trimester went on. They began to realize that my continued Socratic questioning and their own questioning of each other could bring about genuine conceptual change. The experience was very rewarding for many of my students and definitely rewarding for me.

I found that the modeling challenged me to be more creative and student centered in my instruction than I had ever been before. I felt much more invested in the way I was teaching. I also had continual feedback on student understanding due to the fact that students were communicating their ideas in a classroom setting or a lab setting every day. It also allowed students to construct their own understanding in a much 
more personalized way. Although each student performed the same investigations and solved the same problems, there was room for multiple discoveries in each activity and certainly for multiple ways of representing the mental models they were building. I also received a lot of positive feedback from students, parents and my principals regarding the approach that I was implementing.

I was pleasantly surprised to find very little resistance not using a textbook and not teaching in a traditional way. Spring Lake High School is generally a place where there are multiple students with a 4.0 GPA, who are very competitive and are trying to maintain a very impressive high school transcript. Students who succeed in very traditional rote learning types of classes may find it very challenging to succeed in a modeling classroom unless they alter their approach. The difficult transition from wanting to immediately answer correctly to being able to investigate, discuss and formulate mental models was more apparent for certain students. Some inevitably expressed frustration with not being given a direct answer when they asked a question.

On the other hand I found that a modeling approach provided a way for students who might traditionally not be able to succeed in physics to do much better. I was not always able to shift the focus away from myself as the source of answers, but the learning atmosphere was drastically better than in my previous years of teaching in a traditional way. Facilitating a good class discussion was much more challenging than delivering a good interactive lecture, but certainly worthwhile in my estimation. 
The use of multiple representations and following the modeling cycle provided a structure that students became increasingly familiar and confident with. Multiple representations such as motion maps, graphs, data tables, diagrams, for every statements, bridging analogies and various mental models allowed students to engage with the material in a deep, multifaceted way. It challenged them on many levels and also uncovered various aspects of misconceptions they had. For example, misconceptions on position-time, or velocity-time graphs were uncovered when compared with the velocity and acceleration arrows drawn on the motion maps. In other words, if students struggled with a certain representation they could compare it to another and bring clarity to what their primary source of confusion was.

Starting each unit with lab investigations was very rewarding. I observed students not only making observations but also thinking ahead to other scenarios and asking other research questions. Often their questions were answered in later lab investigations. Lab investigations also allowed me to engage with small groups of students in reflecting on what they had observed so far. This was particularly interesting in cases where their results contradicted their predictions. Toward the end of each post-lab whiteboard discussion the students were able to come to a consensus on the answer to their original research question. This served as not only a building block for further investigations but a memorable result that was grounded in a physical context which they had experienced. Students often referred to, or could be reminded 
of, results from previous lab investigations when there was a question that needed to be resolved.

\section{$\mathrm{FCl}$ Results}

During the modeling workshop I had been warned that student performance on the $\mathrm{FCl}$ might not immediately increase during the first few years of modeling instruction. There is much to be learned by the instructor that can only be learned from personal experience. The implementation of a new methodology often involves a lot of adjustment on the part of the instructor and the transition can be challenging. The challenges range from what types of questions to ask on specific worksheet problem discussions to how to present the lab investigations most effectively. Knowing how to challenge students and yet not totally frustrating them is a delicate balance that is difficult to strike. Some students want to be enabled and are very hesitant to take risks. Monitoring multiple lab groups using Socratic questioning and prompting also demands a lot from the instructor. As in any teaching method there are challenges and rewards that become very apparent with experience.

In general, the $\mathrm{FCl}$ pretest scores proved to be rather low as predicted in the literature. However, I was surprised that my 2011 physics class scored as well as they did. Table 1 shows the average of $38 \%$ for Group A on the $\mathrm{FCl}$ pretest. The results for Group B are shown in three different categories since they were given the $\mathrm{FCl}$ as a pre and posttest in both Intro to Physics (IP) and Physics A (PhA). Therefore the $43 \%$ pretest 
average scored by Group B was not the first pretest these students had taken. It was simply their 2012 Physics A pretest. Group B's results are shown separately for their IP $\mathrm{FCl}$ results, their PhA FCI results and their overall IP Pretest to PhA posttest. Of the 62 students in who enrolled in Physics A in 2012, 38 were in Group B. These students had already completed the modeling style Intro to Physics course in 2011. For the remaining 24 Group $\mathrm{C}$ students, it was the first time they had seen the $\mathrm{FCl}$ and the first time they had taken a modeling physics course. As shown in table 1, Group B scored $28 \%$ on their first $\mathrm{FCl}$ pretest while Group C scored nearly the same, 30\%.

\section{TABLE 1: FCI results for Group A, B, C}

\begin{tabular}{|c|c|c|c|c|c|c|c|}
\hline $\begin{array}{l}\text { Type of Instruction } \\
\text { in Intro to Physics: }\end{array}$ & $\begin{array}{l}\text { Course and } \\
\text { Pretest Date }\end{array}$ & $\begin{array}{l}\mathrm{FCl} \\
\text { Pre }\end{array}$ & $\begin{array}{l}\text { Course and } \\
\text { Posttest Date }\end{array}$ & $\begin{array}{l}\mathrm{FCl} \\
\text { Post }\end{array}$ & $\begin{array}{l}\mathrm{FCl} \\
\text { Pre \% }\end{array}$ & $\begin{array}{l}\mathrm{FCl} \\
\text { Post } \\
\%\end{array}$ & $\begin{array}{l}\text { Pre to } \\
\text { Post FCl } \\
<\mathrm{g}\rangle\end{array}$ \\
\hline $\begin{array}{l}\text { Group A } \\
\text { Traditional }(n=38)\end{array}$ & Mod Ph A 2011 & 11.4 & $\begin{array}{l}\text { Mod Ph A } \\
2011\end{array}$ & 18.6 & 38 & 62 & 0.39 \\
\hline $\begin{array}{l}\text { Group B } \\
\text { Modeling, } n=38\end{array}$ & $\begin{array}{l}\text { Mod Ph A } \\
2012\end{array}$ & 12.9 & $\begin{array}{l}\text { Mod Ph A } \\
2012\end{array}$ & 16.5 & 43 & 55 & 0.21 \\
\hline $\begin{array}{l}\text { Group C } \\
\text { Traditional or } \\
\text { Bypassed, } n=24\end{array}$ & $\begin{array}{l}\text { Mod Ph A } \\
2012\end{array}$ & 9.0 & $\begin{array}{l}\text { Mod Ph A } \\
2012\end{array}$ & 13.2 & 30 & 44 & 0.20 \\
\hline $\begin{array}{l}\text { Group B } \\
\text { Modeling, } n=38\end{array}$ & $\begin{array}{l}\text { Mod IP } \\
2011\end{array}$ & 8.3 & $\begin{array}{l}\text { Mod IP } \\
2011\end{array}$ & 15.1 & 28 & 50 & 0.32 \\
\hline $\begin{array}{l}\text { Group B } \\
\text { Modeling, } n=38\end{array}$ & $\begin{array}{l}\text { Mod IP } \\
2011\end{array}$ & 8.3 & $\begin{array}{l}\text { Mod Ph A } \\
2012\end{array}$ & 16.5 & 28 & 55 & 0.38 \\
\hline
\end{tabular}


In 2011, the normalized Hake gain $(<\mathrm{g}>)$ for Group A was 0.39 which nearly matched the novice modeler results reported in the literature. As previously noted, Group A also scored rather well, $38 \%$, on the $\mathrm{FCl}$ pretest. Therefore $\mathrm{a}<\mathrm{g}>$ of 0.39 resulted in an average $\mathrm{FCl}$ posttest score of $62 \%$. In contrast a similar gain was made when the gain was calculated for Group B from the initial 2011 pretest to the 2012 posttest. Essentially $\langle\mathrm{g}\rangle_{\text {GroupA2011 }}$ was equivalent to the overall $\langle\mathrm{g}\rangle_{\text {GroupB2011-2012. }}$ Group A seemed to improve as much in PhA as Group B did over the course of two modeling courses. Perhaps this could be attributed to higher quality class discussions in 2011 or to the fact that the 2011 physics students were just naturally better suited to learn the concepts. Another possible explanation could be that the Newtonian force concept was stronger in Group A to begin with and therefore, their gains were made more efficiently. My recollection is that Group A was a bit more independent and willing to transition into the modeling style of learning than Group C, for example.

There are a various comparisons that can be made between Group B and C. Group B first took the $\mathrm{FCl}$ as sophomores in 2011 . Their $28 \%$ is very comparable to the $\mathrm{FCl}$ pretest score of $30 \%$ for Group C which occurred in PhA in 2012. One interpretation is that Group C entered PhA after either taking a traditional IP or bypassing IP, with a force concept that was equally as poor as Group B did as sophomores entering IP in 2011. Comparing the gains of each group shows that $\langle\mathrm{g}\rangle_{\mathrm{GroupB} 2011}$ in IP was 0.32 while $<\mathrm{g}>_{\text {GroupC2012 }}$ in PhA was only 0.20 . This seems to support the notion that 
preconceptions in Newtonian mechanics are indeed deeply rooted and that Group C was not able to overcome them as well as Group B. Even though Group C students may have felt equally ready to enroll in PhA in 2012 having either bypassed or taken a traditional IP course, the results show otherwise. Furthermore, students who typically bypassed IP were granted permission based on their prior math and science scores. Roughly half of the students in Group C had bypassed IP and the other half had taken a traditional Intro to Physics course in 2010. Although Group C may have been composed of strong traditional students, the results indicate that they performed no better than Group B had in IP. It should be also be noted that PhA was a more rigorous course in which concepts where analyzed on a deeper level. One would think that Group C would learn more from a trimester of PhA than Group B would from a trimester of IP. Perhaps this is further evidence for the need for long term conceptual change. It appears that for Group B and C, making significant gains in developing a Newtonian force concept required more than just one 12-week trimester of a modeling physics course. Again, Group A seems to be the exception to this rule.

The $\langle\mathrm{g}\rangle_{\text {Group B2012 }}(0.21)$ and $\langle\mathrm{g}\rangle_{\text {GroupC2012 }}(0.20)$ are about half as much as $\langle\mathrm{g}\rangle_{\text {GroupA2011 }}(0.39)$. I was expecting $\langle\mathrm{g}\rangle_{\text {GroupB2012 }}$ to be somewhat higher. Perhaps it was more difficult for Group B, having the highest PhA pretest score of $43 \%$, to make equally impressive gains as Group A did in 2011 PhA. Or perhaps this was due to other factors such as the quality of the class discussions in Group A. It may also be relevant to 
consider that 2012 was my second year using the modeling method. I was not always as prepared or ready to anticipate what students would ask next in 2011 . But perhaps this was advantageous in allowing more genuine discussion where students were not as concerned with trying to interpret comments that I may have otherwise interjected. It is possible that In 2012 I was overly active in guiding the discussions, having witnessed a year of modeling. The discrepancy between $\langle\mathrm{g}\rangle_{\text {GroupB2012 }}(0.21)$ and $\langle\mathrm{g}\rangle_{\text {GroupA2011 }}(0.39)$ might be also be viewed as evidence for the detrimental effects of all the fine tuning I did in 2012 to the lab activities or discussions. The fine tuning may also have disrupted the coherence of the modeling sequence in 2012.

In summary, it is premature to claim definite reasons for the results. What can be said for PhA in 2012, is that Group B, having a modeling background in IP made normalized gains that were roughly equal to that of Group C. Group B also appears to have had a better Newtonian force concept at the beginning of Physics A and consequently scored $11 \%$ higher than Group C in Physics A. Group A achieved a large normalized gain (0.39) in 2011. Group B also achieved an overall normalized gain of 0.38 when calculated from the first 2011 Intro to Physics $\mathrm{FCl}$ pretest to the Physics A FCl posttest. Hake (1998) and Hestenes \& Halloun (2005) found similar FCl results that indicated students in modeling courses achieving normalized $\mathrm{FCl}$ gains that were roughly twice as large as the gains made by students in traditional courses. The lack of a true traditional physics class to serve as a comparison group limits the analysis in this study. 
However, the normalized gains near 0.40 are similar to those achieved by novice modelers. Although the data does not necessarily make a convincing argument opposing traditional instruction it does suggest that the modeling method of instruction has promising potential.

\section{$\mathrm{FCl}$ Posttest Score Distributions}

To gain more insight on the results I analyzed the distribution of the $\mathrm{FCl}$ Posttest scores for groups A, B and C (see figures 5-7). The entry threshold to Newtonian thinking is considered to be $60 \%$ as measured by the $\mathrm{FCl}$. Scoring $85 \%$ or higher on the $\mathrm{FCl}$ is considered to indicate Newtonian Mastery. (Hestenes \& Halloun, 1995, p. 505)

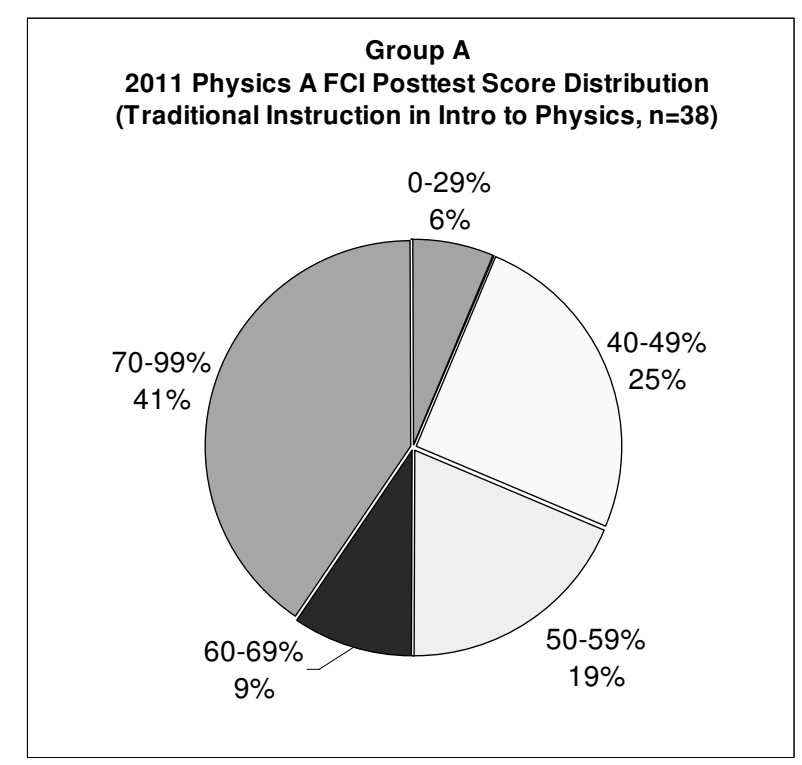

Figure 5 


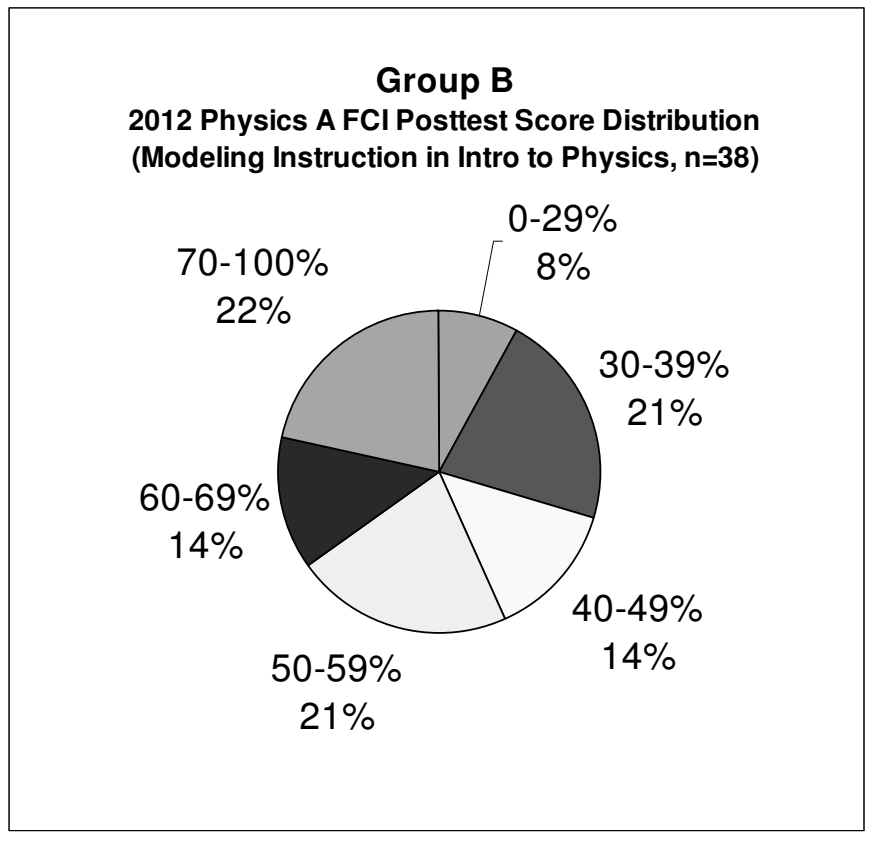

Figure 6

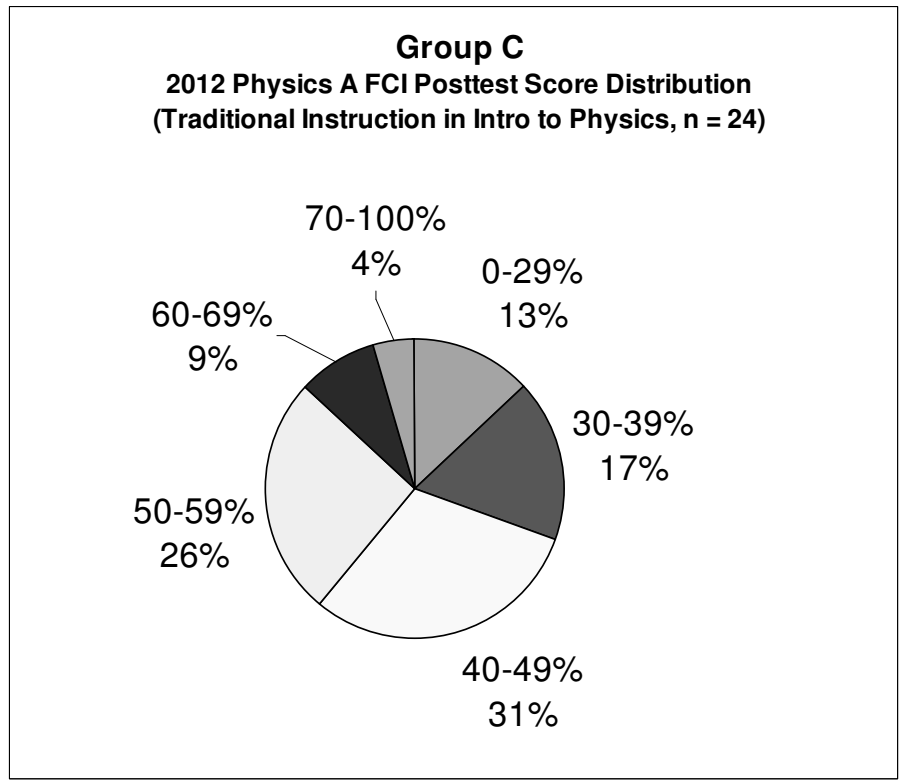

Figure 7 
From the data presented in Figures 5-7, it is clear that the percentage of those scoring above the entry threshold was highest in Group A and B. Half of Group A scored $60 \%$ or higher on the $\mathrm{FCl}$ posttest. For Group B, $36 \%$ scored at least $60 \%$ and $21 \%$ scored in the $50-59 \%$ category. In contrast, only $15 \%$ of students in Group C scored at least $60 \%$. A large percentage (57\%) of students in Group C scored between $40 \%$ and $60 \%$. Perhaps this indicates that many of them were working through many of the same misconceptions and would have made even larger gains had they enrolled in another trimester of a modeling physics course. This again supports the notion of deeply seated preconceptions that are not easily overcome. The validity of the comparison between these three student groups may be debated by some. However, the results do indicate some dramatic differences in the number of students scoring above $60 \%$. At the very least, these results are noteworthy and will serve as a good comparison for future physics classes that I teach.

\section{Newton's Third Law Results}

As previously mentioned, I separately graded the four questions from the $\mathrm{FCl}$ that dealt most directly with Newton's Third Law (N3L). Essentially, I looked at a small subset of questions from the $\mathrm{FCl}$ and calculated the percent correct on the $\mathrm{FCl}$ pretest and posttest. This also made it possible to find the N3L normalized gains $\left(\langle\mathrm{g}\rangle_{\mathrm{N} 3 \mathrm{~L}}\right)$ that students made on this subsection of the $\mathrm{FCl}$. To gain more of a perspective I also tallied the overall $\mathrm{FCl}$ gains $(\langle\mathrm{g}\rangle)$ for the following groups of 
students. The student $\mathrm{FCl}<\mathrm{g}>$ and $\langle\mathrm{g}\rangle_{\mathrm{N} 3 \mathrm{~L}}$ are included in Table 2 and range from 2011 IP to 2013 Physics B.

First of all it should be noted that normalized gains for the Intro to Physics students are not as large, on average, as those in Physics. Perhaps these smaller gains should be somewhat expected at the sophomore level. The Intro to Physics curriculum I used was basically an adaptation of the modeling physics materials, other physical science modeling materials that were gleaned from various sources and lessons of my own additions such as the Bendy Board Lab and the Spring Lab. More work is likely needed in the Intro to Physics curriculum design. It is important to consider both of these indicators since a coherent Newtonian force concept is what is measured by the overall $\mathrm{FCl}$ score and this should not be ignored even if a subset of questions is analyzed.

Let us focus first on the Intro to Physics results in Table 2. It is interesting to note that Group 3 performed better than Group 2 did. Group 2 used electronic force sensors which were more challenging for the students to use. Calibration issues may have also played a role in using the electronic force sensors. Practically speaking, the data collection portion of the Bendy Board Lab was much easier for Group 3 who used mechanical spring scales to measure force (see figure 8). Furthermore, Group 3 had to endure a disrupted winter trimester which included seven snow days. Consequently Group 3 spent very little time learning about projectile motion and 
energy, for example, and this could very well have contributed to slightly lower than expected $\langle\mathrm{g}\rangle_{\text {Group3 }}$ values. Had Group 3 not been subject so many weather related school closings, their results may have further supported the use of mechanical spring scales, both board and spring labs, or other more student centered adaptations to the N3L Lab.

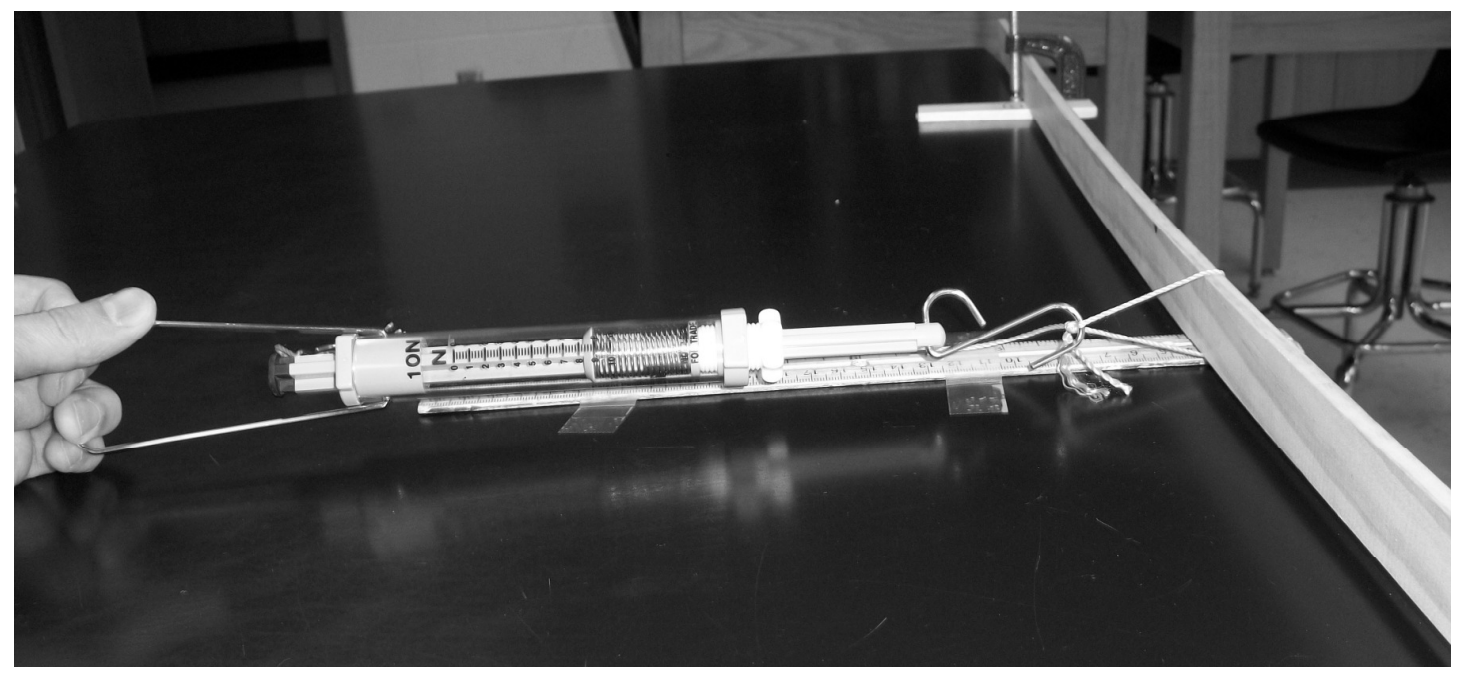

Figure 8 - Mechanical Spring Scale Version of Bendy Board Lab Part 1

It may be expected that a higher $\left\langle\mathrm{g}>_{\mathrm{N} 3 \mathrm{~L}}\right.$ values would correlate well with higher $\langle$ g $\rangle$ values. This was not always the case. Table 2 shows $\langle\mathrm{g}\rangle_{\mathrm{N} 3 \mathrm{~L}, \mathrm{Group} 3}=0.42$ whereas $\langle\mathrm{g}\rangle_{\mathrm{N} 3 \mathrm{~L}, \mathrm{Group} 1}=0.31$ while the $\langle\mathrm{g}\rangle_{\mathrm{Group3}}$ and $\langle\mathrm{g}\rangle_{\mathrm{Group} 1}$ were nearly equal. This seems to suggest that Group 3 made progress specifically in the area of N3L, but apparently did so at a cost. This is demonstrated in the lack of a similar increase in the overall $\mathrm{FCl}<\mathrm{g}>$ for Group 3. Apparently other facets of the Newtonian force 
concept suffered for students in Group 3. Group 3 also investigated the effect of force on the change in length of various springs in the Spring Lab. This may very well have deepened their understanding of N3L force pairs.

I observed that the force and defection data collected for the springs, rather than boards, was often more linear. The boards showed obvious visual evidence that offered key insights into forces exerted by surfaces. However, the Bendy Board data was not as useful in drawing out accurate quantitative comparisons of the force that each board exerted on the other. This was particularly relevant in the case of the primarily sophomore Intro to Physics students. Perhaps the Bendy Board Lab was slightly too technical in nature for all student to be able to analyze the results accurately in a quantitative sense. The process of developing force equations based on deflection for each board was done quite successfully in part 1 of the Board Lab. Part II resulted in mixed results for the students. Perhaps this was partially due to each board not being exactly straight, having warped slightly due to humidity decreases from summer to fall. Having set a pre-load, an initial amount of force, may have produced more linear and convincing lab results. The interpretation of the Board Lab results seemed to be more appropriate for the physics students who were primarily juniors and seniors. Perhaps the qualitative aspects were more appropriate for Intro to Physics whereas the additional quantitative aspects were more appropriate for the Physics students. Using multiple equations that described force 
in relation to the bending amount and the bending of one in relation to bending of another board, may have been a bit too technical at the IP level.

Table 2 - Results for Newton's Third Law related FCl items

\begin{tabular}{|l|c|c|c|l|}
\hline Students & Overall & $\begin{array}{c}\text { \% correct } \\
\text { on N3L FCI } \\
\text { questions }\end{array}$ & $\begin{array}{c}\text { FCI N3L } \\
\text { questions } \\
\text { class } \\
\text { average }<\text { g> }\end{array}$ & \multicolumn{1}{|c|}{ Type of } \\
\hline $\begin{array}{l}\text { Intro to Physics } \\
\text { 2011-12, Group 1, } \\
n=188\end{array}$ & $\mathbf{0 . 2 1}$ & 46 & $\mathbf{0 . 3 1}$ & None \\
\hline $\begin{array}{l}\text { Intro to Physics } \\
\text { Fall 2012, Group 2, } \\
n=55\end{array}$ & $\mathbf{0 . 1 6}$ & 42 & $\mathbf{0 . 2 6}$ & $\begin{array}{l}\text { Board Lab (with } \\
\text { electronic force } \\
\text { sensors) }\end{array}$ \\
\hline $\begin{array}{l}\text { Intro to Physics } \\
\text { Winter2012, Group 3, } \\
n=68\end{array}$ & $\mathbf{0 . 2 0}$ & 54 & $\mathbf{0 . 4 2}$ & $\begin{array}{l}\text { Board Lab (with } \\
\text { spring scales) } \\
\text { and Spring Lab }\end{array}$ \\
\hline $\begin{array}{l}\text { Physics A \& B } \\
\text { 2011-12, Group 4, } \\
n=30\end{array}$ & $\mathbf{0 . 5 3}$ & 75 & $\mathbf{0 . 6 1 8}$ & $\begin{array}{l}\text { None } \\
\text { in Physics B }\end{array}$ \\
\hline $\begin{array}{l}\text { Physics A } \\
\text { Fall 2012, Group 5, } \\
n=60\end{array}$ & $\mathbf{0 . 2 2}$ & 78 & $\mathbf{0 . 6 1 8}$ & $\begin{array}{l}\text { Board Lab (with } \\
\text { electronic force } \\
\text { sensors) }\end{array}$ \\
\hline $\begin{array}{l}\text { Physics A \& B } \\
\text { 2012-13, Group 6, } \\
n=14\end{array}$ & $\mathbf{0 . 4 5}$ & 84 & $\begin{array}{l}\text { Board Lab in PhA } \\
\text { Momentum and } \\
\text { energy were studied } \\
\text { in Physics B }\end{array}$ \\
\hline
\end{tabular}


The amount of student data available for Group 6 is relatively low due to course scheduling and the school trimester schedule. This only allows for limited comparisons between Group 5 and Group 6. However, the comparison may provide some insight into the deeply rooted nature of N3L preconceptions. Assuming that the Group 6 data does not significantly change for the worse once additional data is added to Group 6 after the Spring Trimester, it appears that the study of momentum and collisions play a very important role in the study of N3L.

Another difference in Group 5 and Group 6 might be due to the fact that the added complexity of energy transfer and the partially inelastic nature of collisions was something that Group 5 had not explored, whereas Group 6 had. The data shown for Group 4 was based on instruction in both Physics A and B after studying both momentum and energy. This shows results similar to that of Group 6. Similarly, it will be interesting to see if $\langle\mathrm{g}\rangle_{\mathrm{N} 3 \mathrm{~L}, \mathrm{Group} 6}$ remains larger than $\langle\mathrm{g}\rangle_{\mathrm{N} 3 \mathrm{~L}, \mathrm{Group} 4}$ after the remainder of the data is collected for Group 6 . This might suggest that the addition of the Bendy Board Lab may have influenced the slightly larger $\langle\mathrm{g}\rangle_{\mathrm{N} 3 \mathrm{~L}}$ for Group 6 compared to that of Group 4. 


\section{Chapter 5 - Conclusions}

The first goal of this study was to investigate what effect modeling instruction would have on the normalized gains of students as measured by the Force Concept Inventory? The results seem to be somewhat mixed particularly among Intro to Physics students. However, among the Physics students the results are more convincing. Average normalized FCl gains comparable to those of other novice modelers' students were achieved. There also appears to be a significant difference between students' $\mathrm{FCl}$ performance when comparing the results of those who had a modeling Intro to Physics course and those who had either a traditional Intro to Physics course or chose to bypass Intro to Physics.

A secondary research question was also posed. How could modeling and bridging analogies involving static bend tests be used to promote student learning of Newton's Third Law? Although it is nearly impossible to attribute the addition of certain lab activities to causal evidence of learning specific content, it is possible to look for correlations between these variables. The results indicate that bridging analogies involving static bend tests, as in the Bendy Board Lab, resulted in measurable improvements in student performance on the subset of Newton's Third Law $\mathrm{FCl}$ questions. 


\section{Limitations}

Limitations abound in any study based on student results. However, not all are equally relevant to consider in relation to the questions that were posed in this study and the results that were obtained. The validity of making comparisons between certain student groups may be a source for concern. Although the $<\mathrm{g}>$ values are normalized, each class was taught at a different time, different time of year, and the social interactions in each classroom were varied. However, these variables will always be present in educational research. The fact that the $\langle\mathrm{g}\rangle$ values are normalized is definitely an improvement over simply measuring $\mathrm{FCl}$ posttest results. Although the results cannot be used to claim that modeling instruction will result in certain successes or certain pitfalls for teachers and students it can answer research questions posed by teachers regarding their own students' performance. Appropriate comparisons were made between the $<\mathrm{g}>$ values obtained in this study and other physics education research studies in which the $\mathrm{FCl}$ was used.

Perhaps comparing the success of instructional strategies could be done even more effectively if the same teacher were to teach in a traditional way to one group of students and implemented modeling for another. I chose not to take this approach for three reasons. First, I fully support the modeling method of instruction and wanted to implement it in all of my classes. I also had a large of amount of research results to refer to in order to make some general comparisons. Thirdly, I 
wanted the learning environment to be as natural as possible and my teaching to be as genuine as possible. Had I purposely altered my methods to traditional instruction for some of my classes, I doubt that I could have maintained the same level of enthusiasm for teaching those classes.

The loss of instructional time due to winter weather also likely played a role in the results. This was discussed to some degree earlier. The classes most effected by snow days were those enrolled during the 2013 Winter Trimester. On a related note, not every class was able to cover the same exact amount of content. In a modeling course, the pace is often dependent on the students to some degree. A skillful teacher can sometimes adapt the lessons to allow for the most efficient and meaningful experience for a particular set of students. At times I was able to make those types of adjustments but inevitably each class spent slightly different amounts of time covering each topic.

This pacing challenge was more evident in Intro to Physics. Generally speaking, there were larger disparities in the range understanding of the Newtonian force concept for the students entering Intro to Physics. To say the least, it was challenging to pace the Intro to Physics course and to decide how much depth was appropriate for each topic and how to challenge multiple levels of students at the same time. Having seen how much time can be needed for each topic to be fully 
developed in Physics, the Intro to Physics curriculum remains a work in progress and something that I intend to continually improve.

Another concern might be in the fact that I chose to analyze the student scores on the $\mathrm{N} 3 \mathrm{~L}$ related $\mathrm{FCl}$ questions separately. After all, the $\mathrm{FCl}$ is recommended to be used as a whole and to be used in its entirety. For this reason I included the overall $\mathrm{FCl}<\mathrm{g}>$ values and considered them as well when interpreting the $\mathrm{N} 3 \mathrm{~L}$ results.

Implications

The N3L results for the Physics B students suggest that studying momentum and energy also contribute to a more complete Newtonian concept of force and specifically N3L force pairs. Perhaps the familiarity of collisions occurring in movies, sports, etc., influenced student thinking related to N3L concepts. Even though a student may remember that N3L force pairs are equal and opposite and occur between two objects acting on each other, they may not transfer this belief from a static case to a dynamic case. Again this speaks to the interconnectedness and coherence of Newtonian mechanics. As Camp and Clement (2010) warned against a piecemeal approach separately aimed at specific preconceptions, simply focusing on $\mathrm{N} 3 \mathrm{~L}$ interactions in one context does not guarantee that N3L misconceptions associated with it will be resolved on their own. Preconceptions seem to resurface from time to time, particularly when a new context is introduced. Therefore, certain 
N3L Labs may help students improve their Newtonian force concept but not necessarily overcome all of the common N3L preconceptions.

Some of the lower $<\mathrm{g}>$ results suggest that it was very likely that my continued fine tuning and adjusting of the lessons interrupted some of the coherence of the modeling cycle in certain units. This seems to the case during the 2012 Physics courses more than during the 2011 Physics courses. It also seems to be more evident in Intro to Physics than in Physics as discussed in the previous section. It is likely that the adjustments were improvements on some level but also resulted in unintended consequences such as additional practical or technical challenges in lab activities. Instructors must remain acutely aware of the affects that their adjustments and additions to the curriculum may have. Perhaps in a traditional course these considerations are not as critical if the formulation of the mental models is more teacher-led than student-led. Modeling instructors must have clear outcomes in mind and a carefully planned sequence of investigations prepared for students to engage in. However, a balance needs to exist between a predetermined design provided by the instructor and the freedom for students to engage in the inquiry process on their own terms. If a lab activity is to be student centered and proceed naturally after a research question is posed by the student, then perhaps a unique multi-step inquiry lab aimed at a correct formulation of the concept is too contrived and limits students when developing mental models. 
From the perspective of an Intro to Physics student, the Bendy Board Lab in its existing form may have been somewhat inappropriate. The technical complexity of the proposed post lab analysis and the technical nature of the lab itself might need reconsideration at the Intro to Physics level. It was previously mentioned that some of the force-deflection results were not as linear perhaps they could have been. A possible solution to this could have been applying an initial amount of force, or preload, to the board. If a pre-load had been set then students would also have to start their measurements of deflection relative to the starting position of each pre-loaded board. I wanted to avoid this detail and thought it unnecessary at the time the Bendy Board Lab was implemented. However, in light of the lab results I observed, I may have to consider a pre-load for future Bendy Board Labs. This same technique of setting a pre-load on boards, timbers or logs was something I witnessed this very thing during my MS-ASE Internship, my summer work at MTU's School of Forestry and Wood Products, and my first year and a half of study in MTU's Wood Science program. The relationship between force and deflection in a static bend test is quite linear for a portion of the test. However, there are regions of non-linearity toward the beginning and end of the force-deflection graph, when the board is first loaded and then again before it begins to break, respectively. Perhaps having a better engineered lab apparatus involving force sensors and motion detectors could be used for a physics class. 


\section{Future Research}

The $\mathrm{FCl}$ is an excellent measuring tool for probing students' overall understanding of Newtonian mechanics. $\mathrm{FCl}<\mathrm{g}>$ results have been collected for well over a decade, and therefore provide some ability for teacher to gauge their pedagogical effectiveness in mechanics. However, detailed student interviews could provide more insight into understanding why students tend to cling to specific preconceptions. These interviews might also uncover if or how relevant lab investigations influenced the development of their own mental models or their problem solving strategies. Interviews results may not provide very easily quantifiable results, but may be very useful to an instructor who wishes to gauge the effectiveness of a specific lab activity. On the other hand, the questions posed by the interviewer would need to be posed in such a way as to only elicit spontaneous references to lab investigations done by the students if the researcher wanted to know whether or not students would naturally refer to what they had learned during the lab investigations. Interviewing students about the lab activity specifically might elicit constructive feedback that could influence future adjustments made to the lab activities.

Analyzing $\mathrm{FCl}$ results might also provide insight to the instructor regarding which areas of the Newtonian force concept were the weakest. Research studies have linked $\mathrm{FCl}$ item responses to specific preconceptions held by students in other 
facets of a Newtonian force concept in addition to N3L preconceptions. I am not suggesting addressing misconceptions in isolation from one another, but perhaps the effectiveness of other lab activities could be gauged by analyzing $\mathrm{FCl}$ normalized gains in conjunction with student performance on specific $\mathrm{FCl}$ items. Large gains in specific areas of the $\mathrm{FCl}$ without comparative $<\mathrm{g}>$ values might indicate detrimental effects that the lab activity may have had on students' overall development of a Newtonian force concept. On the other hand, increases in both the overall $\langle\mathrm{g}\rangle$ and on a specific group of $\mathrm{FCl}$ items might support the addition of a certain lab investigation. To improve the effectiveness of a course the instructor needs to look at not only the structure of the course as a whole but also individual elements, such as lab investigations.

Further research devoted to identifying the appropriate technical level of certain N3L labs, as they pertain to grade levels or student ability levels, could also prove very useful to modeling instructors. Further research into the development of the curriculum sequence used for students taking a physics course prior to physics, might also be done in conjunction with research devoted to specific types of labs that should be implemented. Again the use of specific $\mathrm{FCl}$ item analysis or student interviews might be a way to investigate the effects of certain types of labs. How complex or general a lab investigation is may relate to how effectively the students learn the material addressed in the lab. It might also be interesting to investigate 
whether allowing students more freedom in designing their own lab apparatus to investigate relationships such as force and deflection between two objects would provide for a more meaningful learning experience.

Many comparisons have been made between student performance in traditional and modeling classrooms in the last two decades. It may be difficult for a modeling teacher to perform such a study if the teacher is in favor of the modeling method of instruction and doesn't wish to also teach certain classes using traditional methods. Comparing various approaches within the modeling method of instruction may be more realistic. Adjusting the sequence of certain concepts introduced during the course is a very relevant issue for modelers whom I have been in conversation with. For example, some feel that explicitly introducing the concept of force earlier in the course in conjunction with uniform acceleration or even with constant velocity might be beneficial. Since these ideas are not more than hunches that certain modelers have, using $\mathrm{FCl}$ data to make comparisons seems to be worthwhile. Of course there are a multitude of variables that could effect student performance in these comparisons, but perhaps a large enough sample size of $\mathrm{FCl}$ data could provide some insight into which sequence is most effective. This type of study would need to be carried out over a course of years by a group of educators. 


\section{Summary}

The implementation of modeling instruction in physics at Spring Lake High School appears to have resulted in some success. The $\mathrm{FCl}$ gains made my SLHS physics students were quite similar to those of other novice modelers' students published in physics education research studies. Although the comparison between traditional and modeling student groups is not extensive, the distributions of $\mathrm{FCl}$ scores within the groups indicate some significant differences. The 2012 physics results indicate that the largest concentration of $\mathrm{FCl}$ scores above the entry threshold of $60 \%$ occurred within students who had taken only modeling physics courses. Their results were significantly better than the $\mathrm{FCl}$ results for those students who had traditional physics instruction prior to 2012. These results do not suggest guaranteed success for modelers and are not meant to rule out the possibility that traditional courses can be successful. The large body of $\mathrm{FCl}$ research speaks to those comparisons. These results simply shed light on methods that I found to be quite successful during my first two years of implementing modeling instruction in my classroom. Other educators can draw their own conclusions on the relevancy of my findings to their own classroom teaching methods.

The results also indicate that the design and implementation of specific lab investigations such as static bend tests need to be carefully considered. These types 
of bridging analogies seem to fit well into the modeling sequence. To determine which specific lab apparatus provides the best opportunity for student learning related to Newton's Third Law requires more research. I plan to continue to investigate this in future physics classes. It also appears that N3L preconceptions are not fully addressed by static examples. The study of collisions which incorporates impulse and momentum transfer seems to be necessary to gain a more complete understanding of N3L. More FCl data collected in the Spring Trimester of 2013 will allow provide more insight in this area.

No matter the method of instruction, or the students in the classroom, the learning of physics is a process that is affected by many variables. The careful consideration of what effects student learning and how students learn is crucial to its success. It is undeniable that student preconceptions are deeply rooted in experiences, mental constructs and often strengthened by everyday experiences and language. Addressing these preconceptions is no small feat. The enormity of this challenge can be intimidating. Yet, as it often is with many such challenges, it can lead educators to find even better ways to meet them. Our students' preconceptions should not be simply viewed as challenges, however. They are often important building blocks which serve as logical starting points. The modeling method of instruction seems to incorporate this idea well and from my perspective, it has lead to a rich classroom experience for the students as well as their teacher. 


\section{References}

Arons, A. B. (1997). Teaching introductory physics. New York: John Wiley.

Camp, Charles, and John J. Clement (2010). Preconceptions in Mechanics: lessons dealing with students' conceptual difficulties. 2nd ed. College Park, Md.: American Association of Physics Teachers.

Clement, J., Lochhead, J., and Monk, G. S. (1981), "Translation Difficulties in Learning Mathematics," Am. Mathematical Monthly, 88, 286.

Coll, Richard K., France, Bev and Taylor, Ian (2005) "The role of models/and analogies in science education: implications from research," International Journal of Science Education, 27(2), 183-198.

Hake, R. (1998) “Interactive-engagement versus traditional methods: A sixthousand-student survey of mechanics test data for introductory physics courses," American Journal of Physics, 66 (1), 64-71.

Hake, R. (2002) “Relationship of individual Student Normalized Learning Gains in Mechanics with Gender, High-School Physics, and Pretest Scores on Mathematics and Spatial Visualization." Available at http://www.physics.indiana.edu/ hake 
Henderson, Charles (2002). "Common Concerns About the Force Concept Inventory," The Physics Teacher, 40, 542-547.

Hestenes, D. (1987). Toward a modeling theory of instruction. American Journal of Physics, 55(5), 440-454.

Hestenes, D. (2006). Notes for a modeling theory of science cognition and instruction. Proceedings of the 2006 GIREP conference: Modelling in Physics and Physics Education, Amsterdam, Netherlands: University of Amsterdam. Available at http://www.science.uva.nl/research/amstel/dws/girep2006/index.php?Page $\underline{\text { Name }=\text { articles }}$

Hestenes, D. \& Halloun, I. (1995). "Interpreting the force concept inventory." The Physics Teacher, 33, 502-506.

Hestenes, D., Wells, M., \& Swackhamer, G. (1992). "Force Concept Inventory." The Physics Teacher, 30(3), 141-151.

McDermott, L. (1993). "How we teach and how students learn - a mismatch?" American Journal of Physics, 61(4), 295-298. 